\title{
A New Mode of Reactivity for Pyridine N-Oxide: C-H Activation with Uranium(IV) and Thorium(IV) Bis(alkyl) Complexes
}

\author{
Jaime A. Pool, Brian L. Scott, and Jaqueline L. Kiplinger* \\ Chemistry Division, Los Alamos National Laboratory, Los Alamos, NM, 87545, USA.
}

\section{SUPPORTING INFORMATION}

- $\quad$ Full synthesis and characterization data for compounds $\mathbf{1 a}, \mathbf{1 b}, \mathbf{2 a}, \mathbf{2 b}, \mathbf{5 a}$ and $\mathbf{5 b}$.

- $\quad$ Crystallographic data for complexes $\mathbf{1 b}, \mathbf{2 b}, \mathbf{5 a}$, and $\mathbf{5 b}$. 
General Considerations. Unless otherwise noted, reactions and manipulations were performed at $21{ }^{\circ} \mathrm{C}$ in a recirculating Vacuum Atmospheres Model HE-553-2 inert atmosphere $\left(\mathrm{N}_{2}\right.$ or He) drybox with a MO-40-2 Dri-Train, or using standard Schlenk and high vacuum line techniques. Glassware was dried overnight at $150^{\circ} \mathrm{C}$ before use. All NMR spectra were obtained using a Bruker Avance $300 \mathrm{MHz}$ spectrometer. Except when noted, all NMR spectra were acquired at room temperature $\left(21^{\circ} \mathrm{C}\right)$. Benzene- $d_{6}$ was obtained from Cambridge Isotope Laboratories and dried over activated $4 \AA$ molecular sieves prior to use. Chemical shifts were referenced to protio solvent impurities.

Mass spectrometric (MS) analyses were obtained at the University of California, Berkeley mass spectrometry facility on VT-ProSpec, ZAB2-EQ, and 70-FE mass spectrometers. Elemental analyses were performed at the University of California, Berkeley Microanalytical facility on a Perkin Elmer 2400 Series II CHNO/S Analyzer. X-ray data were collected and the structures solved at the Los Alamos National Laboratory X-ray facility using either Bruker P4/CCD or Bruker APEX II CCD diffractometers. Details regarding data collection are provided in the CIF files.

Materials. Unless otherwise noted, reagents were purchased from commercial suppliers and used without further purification. Celite (Aldrich) and alumina (Brockman I, Aldrich) were dried in vacuo at $180^{\circ} \mathrm{C}$ for $48 \mathrm{~h}$ prior to use. Solvents for air- and moisture-sensitive reactions were passed through a column of activated alumina (A2, $12 \times 32$, Purifry) under nitrogen pressure and stored over activated $4 \AA$ molecular sieves. ${ }^{1} \quad$ Pyridine N-oxide (Aldrich) was purified by sublimation prior to use. Lutidine N-oxide (Aldrich) was purified by passage through a column of activated alumina and stored over activated $4 \AA$ molecular sieves prior to use. $\left(\mathrm{C}_{5} \mathrm{Me}_{5}\right)_{2} \mathrm{U}\left(\mathrm{CH}_{3}\right)_{2},\left(\mathrm{C}_{5} \mathrm{Me}_{5}\right)_{2} \mathrm{U}\left(\mathrm{CH}_{2} \mathrm{Ph}\right)_{2},\left(\mathrm{C}_{5} \mathrm{Me}_{5}\right)_{2} \mathrm{Th}\left(\mathrm{CH}_{3}\right)_{2}$, and $\left(\mathrm{C}_{5} \mathrm{Me}_{5}\right)_{2} \mathrm{Th}\left(\mathrm{CH}_{2} \mathrm{Ph}\right)_{2}$ were 
prepared according literature procedures. ${ }^{2}$ Caution: Depleted uranium (primarily isotope ${ }^{238} \mathrm{U}$ ) and natural thorium (isotope ${ }^{232} \mathrm{Th}$ ) are both weak $\alpha$-emitters with a half-life of $4.47 \times 10^{9}$ years and $1.41 \times 10^{10}$ years, respectively. As such, they are principally an internal radiation hazard and inhalation and ingestion need to be avoided.

Preparation of $\left(\mathrm{C}_{5} \mathrm{Me}_{5}\right)_{2} \mathrm{U}\left(\mathrm{CH}_{3}\right)\left[\eta^{2}-(\mathrm{O}, \mathrm{C})-\mathrm{ONC}_{5} \mathrm{H}_{4}\right]$ (1a). A scintillation vial was charged with $\left(\mathrm{C}_{5} \mathrm{Me}_{5}\right)_{2} \mathrm{U}\left(\mathrm{CH}_{3}\right)_{2}(0.250 \mathrm{~g}, 0.464 \mathrm{mmol})$ and approximately $10 \mathrm{~mL}$ of toluene. Pyridine N-oxide (0.066 g, $0.70 \mathrm{mmol})$ was dissolved in approximately $2 \mathrm{~mL}$ of toluene and added to the metallocene solution with stirring. The reaction mixture was stirred for one hour, after which time, the solvent was removed in vacuo. The resulting oil was washed three times with diethyl ether to yield a dark brown-purple solid identified as $\left(\mathrm{C}_{5} \mathrm{Me}_{5}\right)_{2} \mathrm{U}\left(\mathrm{CH}_{3}\right)\left[\eta^{2}-(\mathrm{O}, \mathrm{C})\right.$ $\left.\mathrm{ONC}_{5} \mathrm{H}_{4}\right]$ (1a). The resulting solid was dissolved in a minimal amount of pentane and cooled to $-35{ }^{\circ} \mathrm{C}$ to yield $0.195 \mathrm{~g}(68 \%)$ of $\mathbf{1 a}$ as dark brown crystals. $\mathrm{Mp}=136-139^{\circ} \mathrm{C}$. Anal. Calcd. for $\mathrm{C}_{26} \mathrm{H}_{37} \mathrm{NOU}(617.61 \mathrm{~g} / \mathrm{mol}): \mathrm{C}, 50.56 ; \mathrm{H}, 6.04 ; \mathrm{N}, 2.27$. Found: $\mathrm{C}, 50.22 ; \mathrm{H}, 6.0 ; \mathrm{N}, 2.15$. MS (EI, $70 \mathrm{eV}): m / z 602\left(\mathrm{M}^{+}-\mathrm{Me}\right) .{ }^{1} \mathrm{H}$ NMR (benzene- $\left.d_{6}\right): \delta-17.89\left(\mathrm{~s}, 3 \mathrm{H}, \mathrm{U}-\mathrm{CH}_{3}\right),-1.03(\mathrm{~s}$, $30 \mathrm{H}, \mathrm{C}_{5} M e_{5}$ ), 10.47 (s, broad, 1H, pyrNO), 11.84 (s, broad, 1H, pyrNO), 20.39 (s, broad, 1H, pyrNO), 28.82 (s, broad, 1H, pyrNO).

Preparation of $\left(\mathbf{C}_{5} \mathbf{M e}_{5}\right)_{2} \mathbf{U}\left(\mathbf{C H}_{2} \mathbf{P h}\right)\left[\eta^{2}-(\mathbf{O}, \mathbf{C})-\mathbf{O N C}_{5} \mathbf{H}_{4}\right]$ (1b). A $125 \mathrm{~mL}$ Erlenmeyer flask was charged with $\left(\mathrm{C}_{5} \mathrm{Me}_{5}\right)_{2} \mathrm{U}\left(\mathrm{CH}_{2} \mathrm{Ph}\right)_{2}(0.425 \mathrm{~g}, 0.617 \mathrm{mmol})$ and approximately $30 \mathrm{~mL}$ of toluene. Pyridine N-oxide $(0.088 \mathrm{~g}, 0.93 \mathrm{mmol})$ was dissolved in approximately $2 \mathrm{~mL}$ of toluene and slowly added to the metallocene solution with stirring. The reaction mixture was stirred for one hour, after which, the solvent was removed in vacuo. The resulting oil was washed several times with diethyl ether to yield a dark brown-purple solid identified as $\left(\mathrm{C}_{5} \mathrm{Me}_{5}\right)_{2} \mathrm{U}\left(\mathrm{CH}_{2} \mathrm{Ph}\right)\left[\eta^{2}-\right.$ $\left.(\mathrm{O}, \mathrm{C})-\mathrm{ONC}_{5} \mathrm{H}_{4}\right](\mathbf{1 b})$. The resulting solid was dissolved in a minimal amount of diethyl ether 
and cooled to $-35^{\circ} \mathrm{C}$ to yield $0.282 \mathrm{~g}(66 \%)$ of $\mathbf{1 b}$ as dark brown crystals. Analysis by ${ }^{1} \mathrm{H}$ NMR spectroscopy revealed that samples of $\mathbf{1 b}$ decomposed over time at ambient temperature under inert conditions even in the solid state. Because of this, several attempts at elemental analysis and melting point determination of this complex failed due to decomposition of the isolated product. ${ }^{1} \mathrm{H}$ NMR (benzene- $\left.d_{6}\right): \delta-104.46\left(\mathrm{~s}, 2 \mathrm{H}, \mathrm{CH}_{2} \mathrm{Ph}\right), 1.20\left(\mathrm{~s}, 30 \mathrm{H}, \mathrm{C}_{5} \mathrm{Me}_{5}\right), 3.56(\mathrm{~m}$, broad, $1 \mathrm{H}$, pyrNO), 5.19 (m, broad, 1H, pyrNO), 5.34 (m, broad, 1H, pyrNO), 6.83 (m, broad, 1H, pyrNO), 11.26 (m, 2H, $\left.\mathrm{CH}_{2} P h\right), 11.55$ (m, 1H, $\left.\mathrm{CH}_{2} P h\right), 12.10$ (m, 2H, $\left.\mathrm{CH}_{2} P h\right)$.

Preparation of $\left(\mathrm{C}_{5} \mathrm{Me}_{5}\right)_{2} \mathrm{Th}\left(\mathrm{CH}_{3}\right)\left[\eta^{2}-(\mathrm{O}, \mathrm{C})-\mathrm{ONC}_{5} \mathrm{H}_{4}\right]$ (2a). A scintillation vial was charged with $\left(\mathrm{C}_{5} \mathrm{Me}_{5}\right)_{2} \mathrm{Th}\left(\mathrm{CH}_{3}\right)_{2}(0.150 \mathrm{~g}, 0.282 \mathrm{mmol})$ and approximately $10 \mathrm{~mL}$ of toluene. Pyridine N-oxide $(0.027 \mathrm{~g}, 0.282 \mathrm{mmol})$ was dissolved in approximately $2 \mathrm{~mL}$ of toluene and added to the metallocene solution with stirring. The reaction mixture was stirred for one hour, after which time, the solvent was removed in vacuo. The resulting oil was washed three times with diethyl ether to yield a yellow-white solid identified as $\left(\mathrm{C}_{5} \mathrm{Me}_{5}\right)_{2} \mathrm{Th}\left(\mathrm{CH}_{3}\right)\left[\eta^{2}-(\mathrm{O}, \mathrm{C})\right.$ $\left.\mathrm{ONC}_{5} \mathrm{H}_{4}\right]$ (2a). The resulting solid was dissolved in a minimal amount of diethyl ether and cooled to $-35^{\circ} \mathrm{C}$ to yield $0.144 \mathrm{~g}(84 \%)$ of $2 \mathrm{a}$ as light yellow crystals. $\mathrm{Mp}=149-152{ }^{\circ} \mathrm{C}$. Anal. Calcd. for $\mathrm{C}_{26} \mathrm{H}_{37} \mathrm{NOTh}(611.56 \mathrm{~g} / \mathrm{mol})$ : C, 51.06; H, 6.10; N, 2.29. Found: $\mathrm{C}, 51.37 ; \mathrm{H}, 6.45$; $\mathrm{N}, 2.42 . \mathrm{MS}(\mathrm{EI}, 70 \mathrm{eV}): m / z 596\left(\mathrm{M}^{+}-\mathrm{Me}\right) .{ }^{1} \mathrm{H}$ NMR (benzene- $\left.d_{6}\right): \delta 0.25\left(\mathrm{~s}, 3 \mathrm{H}, \mathrm{Th}-\mathrm{CH}_{3}\right)$, $2.01\left(\mathrm{~s}, 30 \mathrm{H}, \mathrm{C}_{5} M e_{5}\right), 6.20(\mathrm{t}, 1 \mathrm{H}, \mathrm{pyrNO}), 6.66(\mathrm{t}, 1 \mathrm{H}, \mathrm{pyrNO}), 7.33(\mathrm{~d}, 1 \mathrm{H}, \mathrm{pyrNO}), 7.43(\mathrm{~d}$, $1 \mathrm{H}$, pyrNO). ${ }^{13} \mathrm{C}$ NMR (benzene- $\left.d_{6}\right): \delta 11.28\left(\mathrm{C}_{5} \mathrm{Me}_{5}\right), 64.46($ pyrNO$), 67.13\left(\mathrm{Th}-\mathrm{CH}_{3}\right), 121.60$ $\left(C_{5} \mathrm{Me}_{5}\right), 122.08,134.46,135.09$ (pyrNO).

Preparation of $\left(\mathrm{C}_{5} \mathbf{M e}_{5}\right)_{2} \mathbf{T h}\left(\mathrm{CH}_{2} \mathbf{P h}\right)\left[\eta^{2}-(\mathbf{O}, \mathbf{C})-\mathbf{O N C}_{5} \mathbf{H}_{4}\right]$ (2b). A $125 \mathrm{~mL}$ Erlenmeyer flask was charged with $\left(\mathrm{C}_{5} \mathrm{Me}_{5}\right)_{2} \mathrm{Th}\left(\mathrm{CH}_{2} \mathrm{Ph}\right)_{2}(0.250 \mathrm{~g}, 0.366 \mathrm{mmol})$ and approximately $30 \mathrm{~mL}$ of toluene. Pyridine N-oxide $(0.042 \mathrm{~g}, 0.439 \mathrm{mmol})$ was dissolved in approximately $2 \mathrm{~mL}$ of 
toluene and slowly added to the metallocene solution with stirring. The reaction mixture was stirred for 1 hour, after which time, the solvent was removed in vacuo. The resulting oil was washed three times with diethyl ether to yield an orange solid identified as $\left(\mathrm{C}_{5} \mathrm{Me}_{5}\right)_{2} \mathrm{Th}\left(\mathrm{CH}_{2} \mathrm{Ph}\right)\left[\eta^{2}-(\mathrm{O}, \mathrm{C})-\mathrm{ONC}_{5} \mathrm{H}_{4}\right]$. The resulting solid was dissolved in a minimal amount of diethyl ether and cooled to $-35^{\circ} \mathrm{C}$ to yield $0.178 \mathrm{~g}(71 \%)$ of $\mathbf{2 b}$ as yellow-orange crystals. Analysis by ${ }^{1} \mathrm{H}$ NMR spectroscopy revealed that samples of $\mathbf{2} \mathbf{b}$ decomposed over time at ambient temperature under inert conditions even in the solid state. Because of this, several attempts at elemental analysis of this complex failed due to decomposition of the isolated product. $\quad \mathrm{Mp}=124-127{ }^{\circ} \mathrm{C} . \quad{ }^{1} \mathrm{H}$ NMR (benzene- $\left.d_{6}\right): \delta 1.88\left(\mathrm{~s}, 30 \mathrm{H}, \mathrm{C}_{5} M e_{5}\right), 2.03(\mathrm{~s}, 2 \mathrm{H}$, $\left.\mathrm{CH}_{2} \mathrm{Ph}\right), 6.16$ (t, 1H, pyrNO), 6.90 (t, 1H, pyrNO), 7.01 (m, 1H, $\left.\mathrm{CH}_{2} P h\right), 7.32$ (d, 1H, pyrNO), $7.34\left(\mathrm{~d}, 1 \mathrm{H}\right.$ pyrNO), $7.41\left(\mathrm{~m}, 4 \mathrm{H}, \mathrm{CH}_{2} P h\right) .{ }^{13} \mathrm{C}$ NMR (benzene- $\left.d_{6}\right): \delta 11.73\left(\mathrm{C}_{5} \mathrm{Me}_{5}\right), 89.14$ $\left(\mathrm{CH}_{2} \mathrm{Ph}\right), 119.58,122.14,122.58,126.84,129.67,135.05,135.47,155.59\left(\mathrm{pyrNO} / \mathrm{CH}_{2} P h\right)$, $123.20\left(C_{5} \mathrm{Me}_{5}\right)$.

Preparation of Complex 5a. A $125 \mathrm{~mL}$ Erlenmeyer flask was charged with $\left(\mathrm{C}_{5} \mathrm{Me}_{5}\right)_{2} \mathrm{Th}\left(\mathrm{CH}_{3}\right)_{2}(0.313 \mathrm{~g}, 0588 \mathrm{mmol})$ and approximately $30 \mathrm{~mL}$ of toluene. Lutidine $\mathrm{N}-$ oxide $(0.087 \mathrm{~g}, 0.705 \mathrm{mmol})$ was dissolved in approximately $2 \mathrm{~mL}$ of toluene and added to the metallocene solution with stirring. The reaction mixture was stirred for three hours after which time, the solvent was removed in vacuo. The resulting oil was washed with diethyl ether to yield a yellow-white solid identified as $\mathbf{5 a}$. The resulting solid was dissolved in a minimal amount of diethyl ether and cooled to $-35^{\circ} \mathrm{C}$ to yield $0.274 \mathrm{~g}(73 \%)$ of $\mathbf{5 a}$ as light yellow crystals. $\mathrm{Mp}=$ 146-149 ${ }^{\circ} \mathrm{C}$. Anal. Calcd. for $\mathrm{C}_{28} \mathrm{H}_{41} \mathrm{NOTh}(639.66 \mathrm{~g} / \mathrm{mol}):$ C, 52.58; H, 6.46; N, 2.19. Found: C, 52.35; H, 6.53; N, 2.10. MS (EI, $70 \mathrm{eV}): m / z 624\left(\mathrm{M}^{+}-\mathrm{Me}\right) .{ }^{1} \mathrm{H}$ NMR (benzene- $\left.d_{6}\right): \delta 0.19$ (s, 3H, Th- $\mathrm{CH}_{3}$ ), 1.72 (s, 3H, $\mathrm{CH}_{3}$-pyrNO), 2.02 (s, 30H, $\mathrm{C}_{5} \mathrm{Me}_{5}$ ), 2.43 (d, $1 \mathrm{H}, \mathrm{CH}_{2}$-pyrNO), 
other $\mathrm{CH}_{2}$-pyrNO resonance not found, $5.70(\mathrm{~d}, 1 \mathrm{H}$, lutNO), 6.30 (t, 1H, lutNO), $6.41(\mathrm{t}, 1 \mathrm{H}$, lutNO). ${ }^{13} \mathrm{C}$ NMR (benzene- $\left.d_{6}\right): \delta 11.26\left(\mathrm{C}_{5} \mathrm{Me}_{5}\right), 17.97\left(\mathrm{CH}_{3}\right.$-pyrNO), $64.12\left(\mathrm{CH}_{2}\right.$-pyrNO), $68.79\left(\mathrm{Th}-\mathrm{CH}_{3}\right), 121.57\left(C_{5} \mathrm{Me}_{5}\right), 113.20,120.11,129.86,145.56,163.08$ (lutNO).

Preparation of Complex 5b. A $125 \mathrm{~mL}$ Erlenmeyer flask was charged with $\left(\mathrm{C}_{5} \mathrm{Me}_{5}\right)_{2} \mathrm{Th}\left(\mathrm{CH}_{2} \mathrm{Ph}\right)_{2}(0.218 \mathrm{~g}, 0.318 \mathrm{mmol})$ and approximately $30 \mathrm{~mL}$ of toluene. Lutidine $\mathrm{N}-$ oxide $(0.030 \mathrm{~g}, 0.318 \mathrm{mmol})$ was dissolved in approximately $2 \mathrm{~mL}$ of toluene and slowly added to the metallocene solution with stirring. The reaction mixture was stirred for 10 hours, after which time, the solvent was removed in vacuo. The resulting oil was washed three times with diethyl ether to yield a yellow solid identified as $\mathbf{5 b}$. The resulting solid was dissolved in a minimal amount of diethyl ether and cooled to $-35^{\circ} \mathrm{C}$ to yield $0.184 \mathrm{~g}(81 \%)$ of $\mathbf{5 b}$ as yelloworange crystals. $\mathrm{Mp}=123-125^{\circ} \mathrm{C}$. Anal. Calcd. for $\mathrm{C}_{34} \mathrm{H}_{45} \mathrm{NOTh}(715.75 \mathrm{~g} / \mathrm{mol}): \mathrm{C}, 57.05 ; \mathrm{H}$, 6.34; N, 1.96. Found: $\mathrm{C}, 57.44 ; \mathrm{H}, 6.45 ; \mathrm{N}, 2.05 .{ }^{1} \mathrm{H}$ NMR (benzene- $\left.d_{6}\right): \delta 1.76(\mathrm{~s}, 2 \mathrm{H}$, $\left.\mathrm{CH}_{2} \mathrm{Ph}\right), 1.80$ (s, 3H, $\mathrm{CH}_{3}$-pyrNO), 2.02 (s, 30H, $\mathrm{C}_{5} \mathrm{Me}_{5}$ ), 3.17 (m, 2H, $\mathrm{CH}_{2}$-pyrNO), 5.66 (d, $1 \mathrm{H}$, pyrNO), 6.18 (d, 1H, pyrNO), 6.35, 6.92 (t, 1H, $\left.\mathrm{CH}_{2} P h / p y r N O\right), 7.31\left(\mathrm{~d}, 2 \mathrm{H}, \mathrm{CH}_{2} P h\right), 7.41$ (t, $\left.2 \mathrm{H}, \mathrm{CH}_{2} \mathrm{Ph}\right) .{ }^{13} \mathrm{C}$ NMR (benzene- $\left.d_{6}\right): \delta 11.90\left(\mathrm{C}_{5} \mathrm{Me}_{5}\right), 18.47\left(\mathrm{CH}_{3}-\mathrm{pyrNO}\right), 72.52\left(\mathrm{CH}_{2-}\right.$ pyrNO), $86.31\left(\mathrm{CH}_{2} \mathrm{Ph}\right), 115.13,119.31,121.60,123.22,126.48,128.64,145.92,157.06,163.91$ (pyrNO, $\left.\mathrm{CH}_{2} P h\right), 125.96\left(C_{5} \mathrm{Me}_{5}\right)$.

Crystallographic Details for $\left(\mathrm{C}_{5} \mathrm{Me}_{5}\right)_{2} \mathrm{U}\left(\mathrm{CH}_{2} \mathrm{Ph}\right)\left[\eta^{2}-(\mathrm{O}, \mathrm{C})-\mathrm{ONC}_{5} \mathrm{H}_{4}\right]$ (1b). A concentrated hexane solution of $\mathbf{1 b}$ was cooled to $-35^{\circ} \mathrm{C}$. After a few days, dark red crystals were formed. A crystal was chosen and mounted from Paratone $\mathrm{N}$ oil onto a glass fiber under argon gas flow and placed on a Bruker P4/CCD diffractometer, equipped with a Bruker LT-2 temperature device. Data collection and initial indexing and cell refinement were handled using SMART software. ${ }^{3}$ 
Frame integration and final cell parameter calculations were carried out using SAINT software. ${ }^{4}$ The data were corrected for absorption using the SADABS program. ${ }^{5}$ Structure solution, refinement, graphics, and creation of publication materials were performed using SHELXTL. ${ }^{6}$ The structure was solved using direct methods, completed by subsequent difference Fourier techniques, and refined by full-matrix least-squares procedures. Full details of crystal data and structure refinement of $\mathbf{1 b}$ (Figure S1) are shown in Tables S1 and S2:

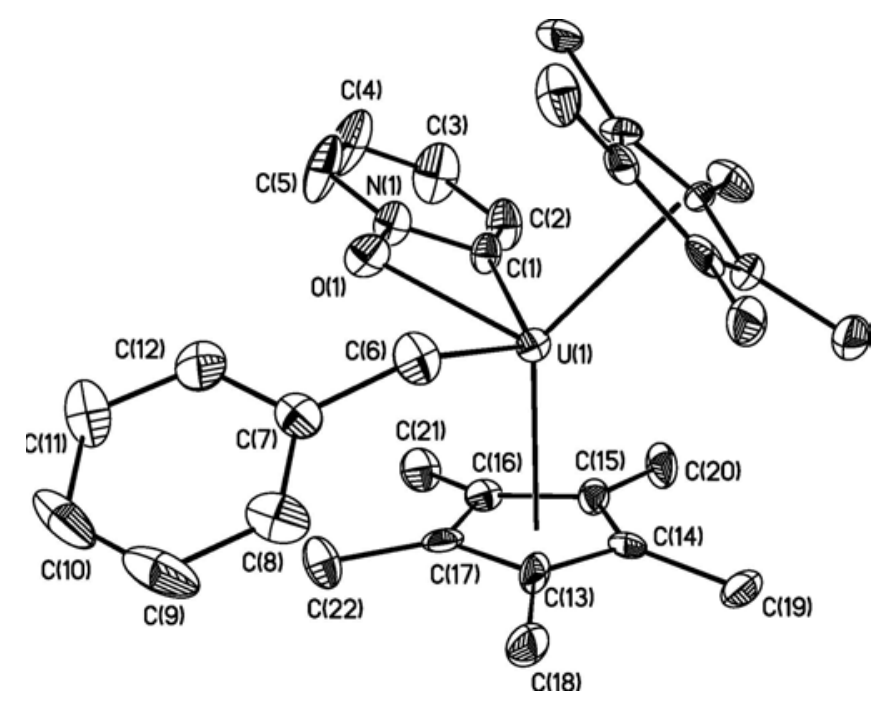

Figure S1. ORTEP diagram of Complex $1 \mathbf{b}$.

Table S1. Crystal data and structure refinement for $\left(\mathrm{C}_{5} \mathrm{Me}_{5}\right)_{2} \mathrm{U}\left(\mathrm{CH}_{2} \mathrm{Ph}\right)\left[\eta^{2}-(\mathrm{O}, \mathrm{C})-\right.$ $\left.\mathrm{ONC}_{5} \mathrm{H}_{4}\right]$ (1b).

Empirical formula

Formula weight

Temperature

Wavelength

Crystal system

Space group
$\mathrm{C}_{32} \mathrm{H}_{41} \mathrm{NOU}$

693.69

203(2) K

$0.71073 \AA$

monoclinic

P 21/n 


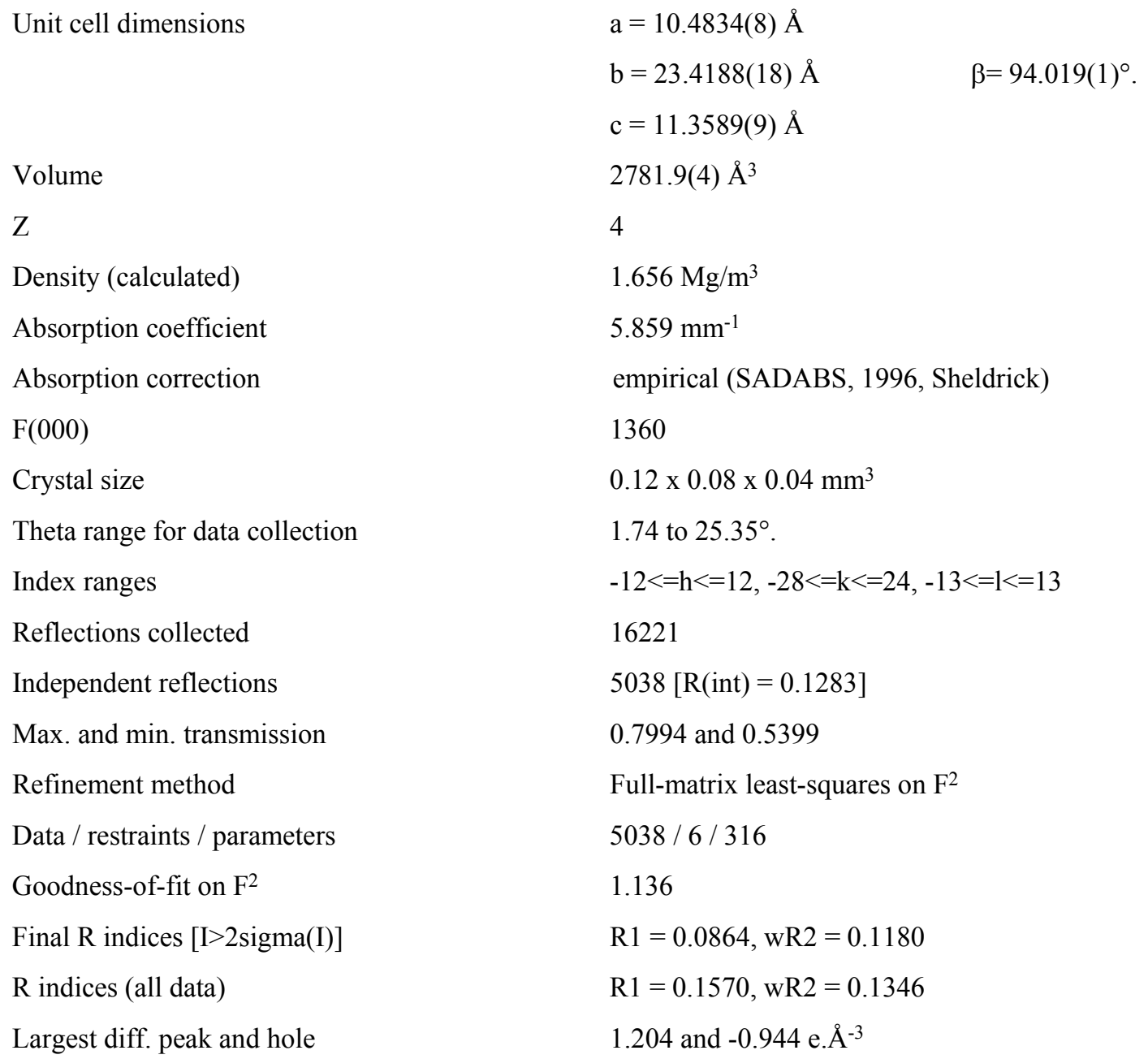

Table S2. Bond lengths $(\AA)$ and angles $\left({ }^{\circ}\right)$ for $\left(\mathrm{C}_{5} \mathrm{Me}_{5}\right)_{2} \mathrm{U}\left(\mathrm{CH}_{2} \mathrm{Ph}\right)\left[\eta^{2}-(\mathrm{O}, \mathrm{C})-\mathrm{ONC}_{5} \mathrm{H}_{4}\right](1 \mathrm{~b})$.

\begin{tabular}{ll}
\hline $\mathrm{U}(1)-\mathrm{O}(1)$ & $2.361(9)$ \\
$\mathrm{U}(1)-\mathrm{C}(6)$ & $2.505(14)$ \\
$\mathrm{U}(1)-\mathrm{C}(1)$ & $2.561(13)$ \\
$\mathrm{U}(1)-\mathrm{C}(24)$ & $2.732(14)$ \\
$\mathrm{U}(1)-\mathrm{C}(17)$ & $2.740(12)$ \\
$\mathrm{U}(1)-\mathrm{C}(13)$ & $2.752(14)$ \\
$\mathrm{U}(1)-\mathrm{C}(16)$ & $2.761(13)$ \\
$\mathrm{U}(1)-\mathrm{C}(15)$ & $2.763(14)$ \\
$\mathrm{U}(1)-\mathrm{C}(25)$ & $2.768(13)$ \\
$\mathrm{U}(1)-\mathrm{C}(14)$ & $2.775(14)$ \\
$\mathrm{U}(1)-\mathrm{C}(26)$ & $2.793(13)$
\end{tabular}




\begin{tabular}{|c|c|}
\hline $\mathrm{U}(1)-\mathrm{C}(23)$ & $2.794(13)$ \\
\hline $\mathrm{N}(1)-\mathrm{C}(5)$ & $1.333(17)$ \\
\hline $\mathrm{N}(1)-\mathrm{C}(1)$ & $1.348(15)$ \\
\hline $\mathrm{N}(1)-\mathrm{O}(1)$ & $1.377(13)$ \\
\hline $\mathrm{C}(1)-\mathrm{C}(2)$ & $1.387(18)$ \\
\hline$C(2)-C(3)$ & $1.39(2)$ \\
\hline$C(3)-C(4)$ & $1.37(2)$ \\
\hline$C(4)-C(5)$ & $1.38(2)$ \\
\hline$C(6)-C(7)$ & $1.483(19)$ \\
\hline$C(7)-C(8)$ & $1.365(19)$ \\
\hline $\mathrm{C}(7)-\mathrm{C}(12)$ & $1.39(2)$ \\
\hline $\mathrm{C}(8)-\mathrm{C}(9)$ & $1.37(2)$ \\
\hline $\mathrm{C}(9)-\mathrm{C}(10)$ & $1.36(2)$ \\
\hline $\mathrm{C}(10)-\mathrm{C}(11)$ & $1.40(2)$ \\
\hline $\mathrm{C}(11)-\mathrm{C}(12)$ & $1.38(2)$ \\
\hline C(13)-C(14) & $1.367(18)$ \\
\hline$C(13)-C(17)$ & $1.431(18)$ \\
\hline C(13)-C(18) & $1.560(18)$ \\
\hline$C(14)-C(15)$ & $1.437(18)$ \\
\hline$C(14)-C(19)$ & $1.502(18)$ \\
\hline$C(15)-C(16)$ & $1.424(18)$ \\
\hline$C(15)-C(20)$ & $1.534(19)$ \\
\hline$C(16)-C(17)$ & $1.416(18)$ \\
\hline$C(16)-C(21)$ & $1.498(17)$ \\
\hline $\mathrm{C}(17)-\mathrm{C}(22)$ & $1.523(19)$ \\
\hline$C(23)-C(24)$ & $1.387(17)$ \\
\hline$C(23)-C(27)$ & $1.432(18)$ \\
\hline$C(23)-C(28)$ & $1.491(17)$ \\
\hline$C(24)-C(25)$ & $1.417(19)$ \\
\hline C(24)-C(29) & $1.526(17)$ \\
\hline$C(25)-C(26)$ & $1.428(19)$ \\
\hline$C(25)-C(30)$ & $1.488(18)$ \\
\hline$C(26)-C(27)$ & $1.426(17)$ \\
\hline$C(26)-C(31)$ & $1.511(18)$ \\
\hline$C(27)-C(32)$ & $1.506(18)$ \\
\hline
\end{tabular}




\begin{tabular}{|c|c|}
\hline $\mathrm{O}(1)-\mathrm{U}(1)-\mathrm{C}(6)$ & $73.6(4)$ \\
\hline $\mathrm{O}(1)-\mathrm{U}(1)-\mathrm{C}(1)$ & $55.1(4)$ \\
\hline$C(6)-U(1)-C(1)$ & $128.6(5)$ \\
\hline $\mathrm{O}(1)-\mathrm{U}(1)-\mathrm{C}(24)$ & $133.4(4)$ \\
\hline $\mathrm{C}(6)-\mathrm{U}(1)-\mathrm{C}(24)$ & $112.9(4)$ \\
\hline $\mathrm{C}(1)-\mathrm{U}(1)-\mathrm{C}(24)$ & $101.3(4)$ \\
\hline $\mathrm{O}(1)-\mathrm{U}(1)-\mathrm{C}(17)$ & $91.1(4)$ \\
\hline $\mathrm{C}(6)-\mathrm{U}(1)-\mathrm{C}(17)$ & $85.6(5)$ \\
\hline $\mathrm{C}(1)-\mathrm{U}(1)-\mathrm{C}(17)$ & $97.1(4)$ \\
\hline $\mathrm{C}(24)-\mathrm{U}(1)-\mathrm{C}(17)$ & $134.4(4)$ \\
\hline $\mathrm{O}(1)-\mathrm{U}(1)-\mathrm{C}(13)$ & $118.9(4)$ \\
\hline $\mathrm{C}(6)-\mathrm{U}(1)-\mathrm{C}(13)$ & $83.5(5)$ \\
\hline $\mathrm{C}(1)-\mathrm{U}(1)-\mathrm{C}(13)$ & $121.7(4)$ \\
\hline $\mathrm{C}(24)-\mathrm{U}(1)-\mathrm{C}(13)$ & $107.7(4)$ \\
\hline $\mathrm{C}(17)-\mathrm{U}(1)-\mathrm{C}(13)$ & $30.2(4)$ \\
\hline $\mathrm{O}(1)-\mathrm{U}(1)-\mathrm{C}(16)$ & $90.7(4)$ \\
\hline $\mathrm{C}(6)-\mathrm{U}(1)-\mathrm{C}(16)$ & $114.1(4)$ \\
\hline $\mathrm{C}(1)-\mathrm{U}(1)-\mathrm{C}(16)$ & $72.6(4)$ \\
\hline $\mathrm{C}(24)-\mathrm{U}(1)-\mathrm{C}(16)$ & $122.6(4)$ \\
\hline $\mathrm{C}(17)-\mathrm{U}(1)-\mathrm{C}(16)$ & $29.8(4)$ \\
\hline $\mathrm{C}(13)-\mathrm{U}(1)-\mathrm{C}(16)$ & $49.1(4)$ \\
\hline $\mathrm{O}(1)-\mathrm{U}(1)-\mathrm{C}(15)$ & $117.7(4)$ \\
\hline$C(6)-U(1)-C(15)$ & $131.1(5)$ \\
\hline$C(1)-U(1)-C(15)$ & $81.2(4)$ \\
\hline $\mathrm{C}(24)-\mathrm{U}(1)-\mathrm{C}(15)$ & $93.1(4)$ \\
\hline $\mathrm{C}(17)-\mathrm{U}(1)-\mathrm{C}(15)$ & $49.1(4)$ \\
\hline $\mathrm{C}(13)-\mathrm{U}(1)-\mathrm{C}(15)$ & $48.4(4)$ \\
\hline$C(16)-U(1)-C(15)$ & $29.9(4)$ \\
\hline $\mathrm{O}(1)-\mathrm{U}(1)-\mathrm{C}(25)$ & $123.1(4)$ \\
\hline$C(6)-U(1)-C(25)$ & $83.2(5)$ \\
\hline $\mathrm{C}(1)-\mathrm{U}(1)-\mathrm{C}(25)$ & $120.7(4)$ \\
\hline $\mathrm{C}(24)-\mathrm{U}(1)-\mathrm{C}(25)$ & $29.9(4)$ \\
\hline $\mathrm{C}(17)-\mathrm{U}(1)-\mathrm{C}(25)$ & $138.7(4)$ \\
\hline $\mathrm{C}(13)-\mathrm{U}(1)-\mathrm{C}(25)$ & $108.7(4)$ \\
\hline $\mathrm{C}(16)-\mathrm{U}(1)-\mathrm{C}(25)$ & $145.8(5)$ \\
\hline $\mathrm{C}(15)-\mathrm{U}(1)-\mathrm{C}(25)$ & $116.7(5)$ \\
\hline
\end{tabular}




\begin{tabular}{|c|c|}
\hline $\mathrm{O}(1)-\mathrm{U}(1)-\mathrm{C}(14)$ & $138.5(4)$ \\
\hline $\mathrm{C}(6)-\mathrm{U}(1)-\mathrm{C}(14)$ & $108.8(5)$ \\
\hline $\mathrm{C}(1)-\mathrm{U}(1)-\mathrm{C}(14)$ & $111.2(4)$ \\
\hline $\mathrm{C}(24)-\mathrm{U}(1)-\mathrm{C}(14)$ & $85.3(4)$ \\
\hline $\mathrm{C}(17)-\mathrm{U}(1)-\mathrm{C}(14)$ & $49.1(4)$ \\
\hline $\mathrm{C}(13)-\mathrm{U}(1)-\mathrm{C}(14)$ & $28.6(4)$ \\
\hline $\mathrm{C}(16)-\mathrm{U}(1)-\mathrm{C}(14)$ & $49.5(4)$ \\
\hline$C(15)-U(1)-C(14)$ & $30.1(4)$ \\
\hline $\mathrm{C}(25)-\mathrm{U}(1)-\mathrm{C}(14)$ & $97.9(5)$ \\
\hline $\mathrm{O}(1)-\mathrm{U}(1)-\mathrm{C}(26)$ & $93.6(4)$ \\
\hline $\mathrm{C}(6)-\mathrm{U}(1)-\mathrm{C}(26)$ & $76.0(4)$ \\
\hline$C(1)-U(1)-C(26)$ & $102.5(4)$ \\
\hline $\mathrm{C}(24)-\mathrm{U}(1)-\mathrm{C}(26)$ & $48.8(4)$ \\
\hline $\mathrm{C}(17)-\mathrm{U}(1)-\mathrm{C}(26)$ & $158.9(4)$ \\
\hline $\mathrm{C}(13)-\mathrm{U}(1)-\mathrm{C}(26)$ & $134.7(4)$ \\
\hline $\mathrm{C}(16)-\mathrm{U}(1)-\mathrm{C}(26)$ & $169.8(4)$ \\
\hline $\mathrm{C}(15)-\mathrm{U}(1)-\mathrm{C}(26)$ & $141.9(4)$ \\
\hline $\mathrm{C}(25)-\mathrm{U}(1)-\mathrm{C}(26)$ & $29.8(4)$ \\
\hline $\mathrm{C}(14)-\mathrm{U}(1)-\mathrm{C}(26)$ & $127.7(4)$ \\
\hline $\mathrm{O}(1)-\mathrm{U}(1)-\mathrm{C}(23)$ & $107.6(3)$ \\
\hline $\mathrm{C}(6)-\mathrm{U}(1)-\mathrm{C}(23)$ & $124.8(4)$ \\
\hline $\mathrm{C}(1)-\mathrm{U}(1)-\mathrm{C}(23)$ & $73.9(4)$ \\
\hline $\mathrm{C}(24)-\mathrm{U}(1)-\mathrm{C}(23)$ & $29.0(4)$ \\
\hline $\mathrm{C}(17)-\mathrm{U}(1)-\mathrm{C}(23)$ & $147.3(4)$ \\
\hline $\mathrm{C}(13)-\mathrm{U}(1)-\mathrm{C}(23)$ & 131.3(4) \\
\hline $\mathrm{C}(16)-\mathrm{U}(1)-\mathrm{C}(23)$ & $121.0(4)$ \\
\hline $\mathrm{C}(15)-\mathrm{U}(1)-\mathrm{C}(23)$ & $98.2(4)$ \\
\hline $\mathrm{C}(25)-\mathrm{U}(1)-\mathrm{C}(23)$ & $48.9(4)$ \\
\hline $\mathrm{C}(14)-\mathrm{U}(1)-\mathrm{C}(23)$ & $104.0(4)$ \\
\hline $\mathrm{C}(26)-\mathrm{U}(1)-\mathrm{C}(23)$ & $48.9(4)$ \\
\hline $\mathrm{C}(5)-\mathrm{N}(1)-\mathrm{C}(1)$ & $128.5(13)$ \\
\hline $\mathrm{C}(5)-\mathrm{N}(1)-\mathrm{O}(1)$ & $117.6(13)$ \\
\hline $\mathrm{C}(1)-\mathrm{N}(1)-\mathrm{O}(1)$ & $113.8(11)$ \\
\hline $\mathrm{C}(5)-\mathrm{N}(1)-\mathrm{U}(1)$ & $170.1(11)$ \\
\hline $\mathrm{C}(1)-\mathrm{N}(1)-\mathrm{U}(1)$ & $61.1(7)$ \\
\hline $\mathrm{O}(1)-\mathrm{N}(1)-\mathrm{U}(1)$ & $52.8(6)$ \\
\hline
\end{tabular}




\begin{tabular}{|c|c|}
\hline $\mathrm{N}(1)-\mathrm{O}(1)-\mathrm{U}(1)$ & $99.5(7)$ \\
\hline $\mathrm{N}(1)-\mathrm{C}(1)-\mathrm{C}(2)$ & $113.7(13)$ \\
\hline N(1)-C(1)-U(1) & $91.5(9)$ \\
\hline $\mathrm{C}(2)-\mathrm{C}(1)-\mathrm{U}(1)$ & $154.8(11)$ \\
\hline $\mathrm{C}(1)-\mathrm{C}(2)-\mathrm{C}(3)$ & $121.1(16)$ \\
\hline $\mathrm{C}(4)-\mathrm{C}(3)-\mathrm{C}(2)$ & $120.6(16)$ \\
\hline$C(3)-C(4)-C(5)$ & $118.9(15)$ \\
\hline $\mathrm{N}(1)-\mathrm{C}(5)-\mathrm{C}(4)$ & $116.9(16)$ \\
\hline$C(7)-C(6)-U(1)$ & $130.9(10)$ \\
\hline $\mathrm{C}(8)-\mathrm{C}(7)-\mathrm{C}(12)$ & $116.7(16)$ \\
\hline $\mathrm{C}(8)-\mathrm{C}(7)-\mathrm{C}(6)$ & $123.4(16)$ \\
\hline $\mathrm{C}(12)-\mathrm{C}(7)-\mathrm{C}(6)$ & $119.8(14)$ \\
\hline $\mathrm{C}(7)-\mathrm{C}(8)-\mathrm{C}(9)$ & $122.5(18)$ \\
\hline $\mathrm{C}(10)-\mathrm{C}(9)-\mathrm{C}(8)$ & $120.8(18)$ \\
\hline $\mathrm{C}(9)-\mathrm{C}(10)-\mathrm{C}(11)$ & $118.5(17)$ \\
\hline $\mathrm{C}(12)-\mathrm{C}(11)-\mathrm{C}(10)$ & $119.4(17)$ \\
\hline $\mathrm{C}(11)-\mathrm{C}(12)-\mathrm{C}(7)$ & $122.1(16)$ \\
\hline$C(14)-C(13)-C(17)$ & $110.0(13)$ \\
\hline $\mathrm{C}(14)-\mathrm{C}(13)-\mathrm{C}(18)$ & $126.0(13)$ \\
\hline $\mathrm{C}(17)-\mathrm{C}(13)-\mathrm{C}(18)$ & $123.8(13)$ \\
\hline $\mathrm{C}(14)-\mathrm{C}(13)-\mathrm{U}(1)$ & $76.6(8)$ \\
\hline $\mathrm{C}(17)-\mathrm{C}(13)-\mathrm{U}(1)$ & $74.4(7)$ \\
\hline $\mathrm{C}(18)-\mathrm{C}(13)-\mathrm{U}(1)$ & $120.1(9)$ \\
\hline$C(13)-C(14)-C(15)$ & $107.4(13)$ \\
\hline$C(13)-C(14)-C(19)$ & $125.5(13)$ \\
\hline$C(15)-C(14)-C(19)$ & $125.0(14)$ \\
\hline $\mathrm{C}(13)-\mathrm{C}(14)-\mathrm{U}(1)$ & $74.7(8)$ \\
\hline $\mathrm{C}(15)-\mathrm{C}(14)-\mathrm{U}(1)$ & $74.5(8)$ \\
\hline C(19)-C(14)-U(1) & $129.4(10)$ \\
\hline$C(16)-C(15)-C(14)$ & $108.2(13)$ \\
\hline$C(16)-C(15)-C(20)$ & $124.9(14)$ \\
\hline$C(14)-C(15)-C(20)$ & $126.7(14)$ \\
\hline $\mathrm{C}(16)-\mathrm{C}(15)-\mathrm{U}(1)$ & $75.0(8)$ \\
\hline $\mathrm{C}(14)-\mathrm{C}(15)-\mathrm{U}(1)$ & $75.4(8)$ \\
\hline$C(20)-C(15)-U(1)$ & $120.4(9)$ \\
\hline$C(17)-C(16)-C(15)$ & $107.2(13)$ \\
\hline
\end{tabular}




\begin{tabular}{|c|c|}
\hline$C(17)-C(16)-C(21)$ & $123.9(14)$ \\
\hline$C(15)-C(16)-C(21)$ & $128.3(14)$ \\
\hline $\mathrm{C}(17)-\mathrm{C}(16)-\mathrm{U}(1)$ & 74.3(7) \\
\hline$C(15)-C(16)-U(1)$ & $75.1(8)$ \\
\hline $\mathrm{C}(21)-\mathrm{C}(16)-\mathrm{U}(1)$ & $123.1(9)$ \\
\hline$C(16)-C(17)-C(13)$ & $107.2(14)$ \\
\hline $\mathrm{C}(16)-\mathrm{C}(17)-\mathrm{C}(22)$ & $123.0(13)$ \\
\hline $\mathrm{C}(13)-\mathrm{C}(17)-\mathrm{C}(22)$ & $129.4(13)$ \\
\hline $\mathrm{C}(16)-\mathrm{C}(17)-\mathrm{U}(1)$ & $75.9(7)$ \\
\hline C(13)-C(17)-U(1) & $75.3(8)$ \\
\hline $\mathrm{C}(22)-\mathrm{C}(17)-\mathrm{U}(1)$ & $120.3(9)$ \\
\hline $\mathrm{C}(24)-\mathrm{C}(23)-\mathrm{C}(27)$ & $107.3(12)$ \\
\hline $\mathrm{C}(24)-\mathrm{C}(23)-\mathrm{C}(28)$ & $126.4(13)$ \\
\hline $\mathrm{C}(27)-\mathrm{C}(23)-\mathrm{C}(28)$ & $126.0(12)$ \\
\hline $\mathrm{C}(24)-\mathrm{C}(23)-\mathrm{U}(1)$ & $73.0(8)$ \\
\hline C(27)-C(23)-U(1) & $75.2(7)$ \\
\hline C(28)-C(23)-U(1) & $121.8(9)$ \\
\hline $\mathrm{C}(23)-\mathrm{C}(24)-\mathrm{C}(25)$ & $110.3(13)$ \\
\hline$C(23)-C(24)-C(29)$ & $123.1(14)$ \\
\hline $\mathrm{C}(25)-\mathrm{C}(24)-\mathrm{C}(29)$ & $124.4(14)$ \\
\hline C(23)-C(24)-U(1) & $78.0(8)$ \\
\hline$C(25)-C(24)-U(1)$ & $76.5(8)$ \\
\hline C(29)-C(24)-U(1) & $126.5(9)$ \\
\hline$C(24)-C(25)-C(26)$ & $106.8(12)$ \\
\hline $\mathrm{C}(24)-\mathrm{C}(25)-\mathrm{C}(30)$ & $126.4(15)$ \\
\hline$C(26)-C(25)-C(30)$ & $126.6(14)$ \\
\hline $\mathrm{C}(24)-\mathrm{C}(25)-\mathrm{U}(1)$ & $73.7(8)$ \\
\hline$C(26)-C(25)-U(1)$ & 76.1(7) \\
\hline$C(30)-C(25)-U(1)$ & 119.0(9) \\
\hline$C(27)-C(26)-C(25)$ & $107.7(13)$ \\
\hline $\mathrm{C}(27)-\mathrm{C}(26)-\mathrm{C}(31)$ & $124.3(13)$ \\
\hline$C(25)-C(26)-C(31)$ & $127.1(13)$ \\
\hline $\mathrm{C}(27)-\mathrm{C}(26)-\mathrm{U}(1)$ & 75.3(7) \\
\hline$C(25)-C(26)-U(1)$ & 74.1(7) \\
\hline$C(31)-C(26)-U(1)$ & $125.1(9)$ \\
\hline$C(26)-C(27)-C(23)$ & $107.9(12)$ \\
\hline
\end{tabular}


C(26)-C(27)-C(32)

$\mathrm{C}(23)-\mathrm{C}(27)-\mathrm{C}(32)$

$\mathrm{C}(26)-\mathrm{C}(27)-\mathrm{U}(1)$

$\mathrm{C}(23)-\mathrm{C}(27)-\mathrm{U}(1)$

$\mathrm{C}(32)-\mathrm{C}(27)-\mathrm{U}(1)$
125.5(14)

126.2(12)

75.2(7)

75.1(7)

122.0(9)

Crystallographic Details for $\left(\mathrm{C}_{5} \mathrm{Me}_{5}\right)_{2} \mathrm{Th}\left(\mathrm{CH}_{2} \mathrm{Ph}\right)\left[\eta^{2}-(\mathrm{O}, \mathrm{C})-\mathrm{ONC}_{5} \mathrm{H}_{4}\right](2 \mathrm{~b})$. A concentrated diethyl ether solution of $\mathbf{2} \mathbf{b}$ was cooled to $-35^{\circ} \mathrm{C}$. After a few days, yellow crystals were formed. A crystal was chosen and mounted from Paratone $\mathrm{N}$ oil onto a glass fiber under argon gas flow and placed on a Bruker APEX II CCD diffractometer, equipped with a Bruker Kryoflex low temperature device. Data collection and initial indexing and cell refinement were handled using APEX II software. ${ }^{5}$ Frame integration and final cell parameter calculations were carried out using SAINT software. ${ }^{6}$ The data were corrected for absorption using the SADABS program. ${ }^{7}$ Structure solution, refinement, graphics, and creation of publication materials were performed using SHELXTL. ${ }^{8}$ The structure was solved using direct methods, completed by subsequent difference Fourier techniques, and refined by full-matrix least-squares procedures. Full details of crystal data and structure refinement of $\mathbf{2 b}$ (Figure S2) are shown in Tables S3 and S4. 


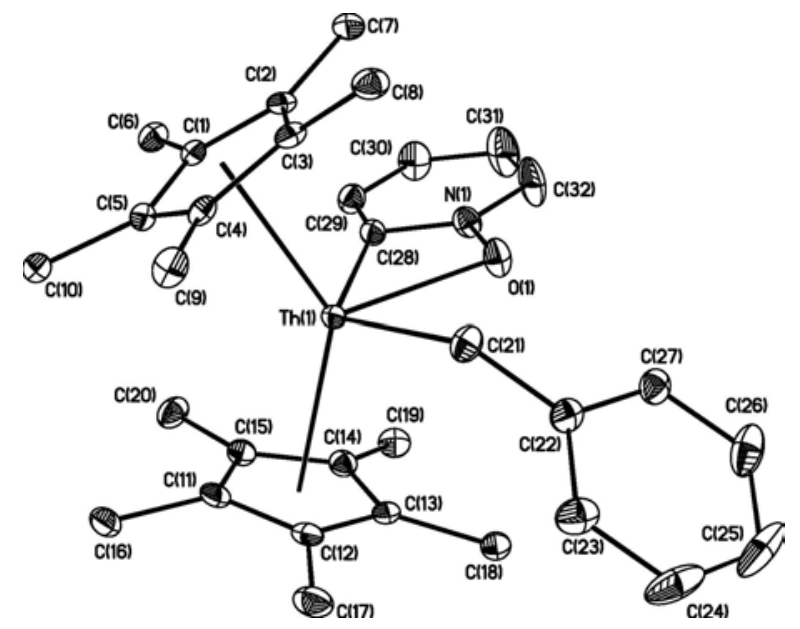

Figure S2. ORTEP diagram of Complex $2 \mathbf{b}$.

Table S3. Crystal data and structure refinement for $\left(\mathrm{C}_{5} \mathrm{Me}_{5}\right)_{2} \mathrm{Th}\left(\mathrm{CH}_{2} \mathrm{Ph}\right)\left[\eta^{2}-(\mathrm{O}, \mathrm{C})-\right.$ $\left.\mathrm{ONC}_{5} \mathrm{H}_{4}\right]$ (2b).

\begin{tabular}{|c|c|c|}
\hline Empirical formula & \multicolumn{2}{|l|}{$\mathrm{C}_{32} \mathrm{H}_{41} \mathrm{~N} \mathrm{O} \mathrm{Th}$} \\
\hline Formula weight & \multicolumn{2}{|l|}{687.70} \\
\hline Temperature & \multicolumn{2}{|l|}{$203(2) \mathrm{K}$} \\
\hline Wavelength & \multicolumn{2}{|l|}{$0.71073 \AA$} \\
\hline Crystal system & \multicolumn{2}{|l|}{ monoclinic } \\
\hline Space group & \multicolumn{2}{|l|}{$\mathrm{P} 2{ }_{1} / \mathrm{n}$} \\
\hline \multirow[t]{3}{*}{ Unit cell dimensions } & $\mathrm{a}=10.4583(4) \AA$ & $\alpha=90^{\circ}$ \\
\hline & $\mathrm{b}=23.2441(8) \AA$ & $\beta=93.6720(10)^{\circ}$ \\
\hline & $\mathrm{c}=11.4942(4) \AA$ & $\gamma=90^{\circ}$ \\
\hline Volume & \multicolumn{2}{|l|}{$2788.43(17) \AA^{3}$} \\
\hline $\mathrm{Z}$ & \multicolumn{2}{|l|}{4} \\
\hline Density (calculated) & \multicolumn{2}{|l|}{$1.638 \mathrm{Mg} / \mathrm{m}^{3}$} \\
\hline Absorption coefficient & \multicolumn{2}{|l|}{$5.372 \mathrm{~mm}^{-1}$} \\
\hline $\mathrm{F}(000)$ & \multicolumn{2}{|l|}{1352} \\
\hline Crystal size & \multicolumn{2}{|c|}{$0.20 \times 0.20 \times 0.12 \mathrm{~mm}^{3}$} \\
\hline Theta range for data collection & \multicolumn{2}{|c|}{1.75 to $28.96^{\circ}$} \\
\hline Index ranges & \multicolumn{2}{|c|}{$-13<=\mathrm{h}<=13,-30<=\mathrm{k}<=31,-15<=1<=15$} \\
\hline Reflections collected & \multicolumn{2}{|l|}{27423} \\
\hline
\end{tabular}


Independent reflections

Completeness to theta $=25.00^{\circ}$

Max. and min. transmission

Refinement method

Data / restraints / parameters

Goodness-of-fit on $\mathrm{F}^{2}$

Final R indices [I $>2 \operatorname{sigma}(\mathrm{I})]$

$\mathrm{R}$ indices (all data)

Largest diff. peak and hole
$6861[\mathrm{R}(\mathrm{int})=0.0302]$

$100.0 \%$

0.5650 and 0.4130

Full-matrix least-squares on $\mathrm{F}^{2}$

$6861 / 0 / 322$

1.137

$\mathrm{R} 1=0.0231, \mathrm{wR} 2=0.0595$

$\mathrm{R} 1=0.0319, \mathrm{wR} 2=0.0614$

0.994 and -0.765 e. $\AA^{-3}$

Table S4. Bond lengths $(\AA)$ and angles $\left({ }^{\circ}\right)$ for $\left(\mathrm{C}_{5} \mathrm{Me}_{5}\right)_{2} \mathrm{Th}\left(\mathrm{CH}_{2} \mathrm{Ph}\right)\left[\eta^{2}-(\mathrm{O}, \mathrm{C})-\mathrm{ONC}_{5} \mathrm{H}_{4}\right](2 \mathrm{~b})$.

\begin{tabular}{ll}
\hline $\operatorname{Th}(1)-\mathrm{O}(1)$ & $2.416(2)$ \\
$\operatorname{Th}(1)-\mathrm{C}(21)$ & $2.575(3)$ \\
$\operatorname{Th}(1)-\mathrm{C}(28)$ & $2.621(3)$ \\
$\operatorname{Th}(1)-\mathrm{C}(1)$ & $2.811(3)$ \\
$\operatorname{Th}(1)-\mathrm{C}(13)$ & $2.812(3)$ \\
$\operatorname{Th}(1)-\mathrm{C}(14)$ & $2.814(3)$ \\
$\operatorname{Th}(1)-\mathrm{C}(5)$ & $2.816(3)$ \\
$\operatorname{Th}(1)-\mathrm{C}(12)$ & $2.823(3)$ \\
$\operatorname{Th}(1)-\mathrm{C}(4)$ & $2.825(3)$ \\
$\operatorname{Th}(1)-\mathrm{C}(15)$ & $2.834(3)$ \\
$\operatorname{Th}(1)-\mathrm{C}(11)$ & $2.838(3)$ \\
$\operatorname{Th}(1)-\mathrm{C}(2)$ & $2.840(3)$ \\
$\mathrm{N}(1)-\mathrm{C}(32)$ & $1.349(4)$ \\
$\mathrm{N}(1)-\mathrm{C}(28)$ & $1.351(4)$ \\
$\mathrm{N}(1)-\mathrm{O}(1)$ & $1.360(3)$ \\
$\mathrm{C}(1)-\mathrm{C}(2)$ & $1.422(4)$ \\
$\mathrm{C}(1)-\mathrm{C}(5)$ & $1.424(4)$ \\
$\mathrm{C}(1)-\mathrm{C}(6)$ & $1.507(4)$ \\
$\mathrm{C}(2)-\mathrm{C}(3)$ & $1.417(4)$ \\
$\mathrm{C}(2)-\mathrm{C}(7)$ & $1.504(4)$ \\
$\mathrm{C}(3)-\mathrm{C}(4)$ & $1.430(4)$ \\
&
\end{tabular}




\begin{tabular}{|c|c|}
\hline$C(3)-C(8)$ & $1.500(4)$ \\
\hline$C(4)-C(5)$ & $1.426(4)$ \\
\hline $\mathrm{C}(4)-\mathrm{C}(9)$ & $1.493(4)$ \\
\hline$C(5)-C(10)$ & $1.494(4)$ \\
\hline $\mathrm{C}(11)-\mathrm{C}(15)$ & $1.417(5)$ \\
\hline $\mathrm{C}(11)-\mathrm{C}(12)$ & $1.427(5)$ \\
\hline $\mathrm{C}(11)-\mathrm{C}(16)$ & $1.517(4)$ \\
\hline $\mathrm{C}(12)-\mathrm{C}(13)$ & $1.420(4)$ \\
\hline $\mathrm{C}(12)-\mathrm{C}(17)$ & $1.490(5)$ \\
\hline$C(13)-C(14)$ & $1.422(5)$ \\
\hline $\mathrm{C}(13)-\mathrm{C}(18)$ & $1.516(4)$ \\
\hline$C(14)-C(15)$ & $1.415(5)$ \\
\hline$C(14)-C(19)$ & $1.508(5)$ \\
\hline$C(15)-C(20)$ & $1.512(4)$ \\
\hline $\mathrm{C}(21)-\mathrm{C}(22)$ & $1.481(5)$ \\
\hline $\mathrm{C}(22)-\mathrm{C}(23)$ & $1.388(5)$ \\
\hline$C(22)-C(27)$ & $1.403(5)$ \\
\hline$C(23)-C(24)$ & $1.381(5)$ \\
\hline$C(24)-C(25)$ & $1.393(6)$ \\
\hline$C(25)-C(26)$ & $1.388(6)$ \\
\hline$C(26)-C(27)$ & $1.383(5)$ \\
\hline C(28)-C(29) & $1.400(5)$ \\
\hline C(29)-C(30) & $1.373(5)$ \\
\hline $\mathrm{C}(30)-\mathrm{C}(31)$ & $1.372(5)$ \\
\hline $\mathrm{C}(31)-\mathrm{C}(32)$ & $1.352(5)$ \\
\hline $\mathrm{O}(1)-\mathrm{Th}(1)-\mathrm{C}(21)$ & $73.11(9)$ \\
\hline $\mathrm{O}(1)-\mathrm{Th}(1)-\mathrm{C}(28)$ & 53.91(9) \\
\hline $\mathrm{C}(21)-\mathrm{Th}(1)-\mathrm{C}(28)$ & $126.75(11)$ \\
\hline $\mathrm{O}(1)-\mathrm{Th}(1)-\mathrm{C}(1)$ & $108.53(9)$ \\
\hline $\mathrm{C}(21)-\mathrm{Th}(1)-\mathrm{C}(1)$ & $122.90(10)$ \\
\hline $\mathrm{C}(28)-\mathrm{Th}(1)-\mathrm{C}(1)$ & $75.05(10)$ \\
\hline $\mathrm{O}(1)-\mathrm{Th}(1)-\mathrm{C}(13)$ & $89.79(9)$ \\
\hline $\mathrm{C}(21)-\mathrm{Th}(1)-\mathrm{C}(13)$ & $86.83(10)$ \\
\hline $\mathrm{C}(28)-\mathrm{Th}(1)-\mathrm{C}(13)$ & $97.12(10)$ \\
\hline $\mathrm{C}(1)-\mathrm{Th}(1)-\mathrm{C}(13)$ & $148.14(9)$ \\
\hline
\end{tabular}




\begin{tabular}{|c|c|}
\hline $\mathrm{O}(1)-\mathrm{Th}(1)-\mathrm{C}(14)$ & $89.40(9)$ \\
\hline $\mathrm{C}(21)-\mathrm{Th}(1)-\mathrm{C}(14)$ & $114.64(10)$ \\
\hline $\mathrm{C}(28)-\mathrm{Th}(1)-\mathrm{C}(14)$ & $73.35(10)$ \\
\hline$C(1)-T h(1)-C(14)$ & $122.40(9)$ \\
\hline $\mathrm{C}(13)-\mathrm{Th}(1)-\mathrm{C}(14)$ & $29.28(9)$ \\
\hline $\mathrm{O}(1)-\mathrm{Th}(1)-\mathrm{C}(5)$ & $134.60(9)$ \\
\hline $\mathrm{C}(21)-\mathrm{Th}(1)-\mathrm{C}(5)$ & $111.46(10)$ \\
\hline$C(28)-T h(1)-C(5)$ & $102.81(9)$ \\
\hline $\mathrm{C}(1)-\mathrm{Th}(1)-\mathrm{C}(5)$ & $29.31(8)$ \\
\hline $\mathrm{C}(13)-\mathrm{Th}(1)-\mathrm{C}(5)$ & 134.64(9) \\
\hline $\mathrm{C}(14)-\mathrm{Th}(1)-\mathrm{C}(5)$ & $123.68(9)$ \\
\hline $\mathrm{O}(1)-\mathrm{Th}(1)-\mathrm{C}(12)$ & $116.53(9)$ \\
\hline $\mathrm{C}(21)-\mathrm{Th}(1)-\mathrm{C}(12)$ & $84.41(11)$ \\
\hline $\mathrm{C}(28)-\mathrm{Th}(1)-\mathrm{C}(12)$ & $121.58(10)$ \\
\hline $\mathrm{C}(1)-\mathrm{Th}(1)-\mathrm{C}(12)$ & $132.81(9)$ \\
\hline $\mathrm{C}(13)-\mathrm{Th}(1)-\mathrm{C}(12)$ & $29.19(9)$ \\
\hline $\mathrm{C}(14)-\mathrm{Th}(1)-\mathrm{C}(12)$ & $48.23(9)$ \\
\hline $\mathrm{C}(5)-\mathrm{Th}(1)-\mathrm{C}(12)$ & $108.85(9)$ \\
\hline $\mathrm{O}(1)-\mathrm{Th}(1)-\mathrm{C}(4)$ & $124.06(9)$ \\
\hline $\mathrm{C}(21)-\mathrm{Th}(1)-\mathrm{C}(4)$ & $82.32(10)$ \\
\hline $\mathrm{C}(28)-\mathrm{Th}(1)-\mathrm{C}(4)$ & $121.13(10)$ \\
\hline $\mathrm{C}(1)-\mathrm{Th}(1)-\mathrm{C}(4)$ & $48.37(9)$ \\
\hline $\mathrm{C}(13)-\mathrm{Th}(1)-\mathrm{C}(4)$ & $138.73(9)$ \\
\hline $\mathrm{C}(14)-\mathrm{Th}(1)-\mathrm{C}(4)$ & $146.32(10)$ \\
\hline $\mathrm{C}(5)-\mathrm{Th}(1)-\mathrm{C}(4)$ & $29.28(9)$ \\
\hline $\mathrm{C}(12)-\mathrm{Th}(1)-\mathrm{C}(4)$ & 109.81(9) \\
\hline $\mathrm{O}(1)-\mathrm{Th}(1)-\mathrm{C}(15)$ & $115.72(9)$ \\
\hline $\mathrm{C}(21)-\mathrm{Th}(1)-\mathrm{C}(15)$ & $131.70(11)$ \\
\hline $\mathrm{C}(28)-\mathrm{Th}(1)-\mathrm{C}(15)$ & 81.91(10) \\
\hline $\mathrm{C}(1)-\mathrm{Th}(1)-\mathrm{C}(15)$ & $100.08(9)$ \\
\hline $\mathrm{C}(13)-\mathrm{Th}(1)-\mathrm{C}(15)$ & $48.06(9)$ \\
\hline $\mathrm{C}(14)-\mathrm{Th}(1)-\mathrm{C}(15)$ & 29.03(9) \\
\hline $\mathrm{C}(5)-\mathrm{Th}(1)-\mathrm{C}(15)$ & $94.95(10)$ \\
\hline$C(12)-\operatorname{Th}(1)-C(15)$ & $48.20(10)$ \\
\hline $\mathrm{C}(4)-\mathrm{Th}(1)-\mathrm{C}(15)$ & $118.14(9)$ \\
\hline $\mathrm{O}(1)-\mathrm{Th}(1)-\mathrm{C}(11)$ & $135.59(9)$ \\
\hline
\end{tabular}




\begin{tabular}{|c|c|}
\hline $\mathrm{C}(21)-\mathrm{Th}(1)-\mathrm{C}(11)$ & $110.57(11)$ \\
\hline $\mathrm{C}(28)-\mathrm{Th}(1)-\mathrm{C}(11)$ & $110.80(10)$ \\
\hline $\mathrm{C}(1)-\mathrm{Th}(1)-\mathrm{C}(11)$ & $105.34(9)$ \\
\hline $\mathrm{C}(13)-\mathrm{Th}(1)-\mathrm{C}(11)$ & $47.83(9)$ \\
\hline $\mathrm{C}(14)-\mathrm{Th}(1)-\mathrm{C}(11)$ & $47.73(9)$ \\
\hline$C(5)-\operatorname{Th}(1)-C(11)$ & $86.89(9)$ \\
\hline $\mathrm{C}(12)-\mathrm{Th}(1)-\mathrm{C}(11)$ & $29.19(10)$ \\
\hline$C(4)-\operatorname{Th}(1)-C(11)$ & $99.88(9)$ \\
\hline $\mathrm{C}(15)-\mathrm{Th}(1)-\mathrm{C}(11)$ & 28.93(9) \\
\hline $\mathrm{O}(1)-\mathrm{Th}(1)-\mathrm{C}(2)$ & $86.63(9)$ \\
\hline $\mathrm{C}(21)-\mathrm{Th}(1)-\mathrm{C}(2)$ & $98.80(10)$ \\
\hline $\mathrm{C}(28)-\mathrm{Th}(1)-\mathrm{C}(2)$ & $75.12(10)$ \\
\hline $\mathrm{C}(1)-\mathrm{Th}(1)-\mathrm{C}(2)$ & $29.15(8)$ \\
\hline $\mathrm{C}(13)-\mathrm{Th}(1)-\mathrm{C}(2)$ & $172.13(9)$ \\
\hline $\mathrm{C}(14)-\mathrm{Th}(1)-\mathrm{C}(2)$ & $143.51(9)$ \\
\hline $\mathrm{C}(5)-\mathrm{Th}(1)-\mathrm{C}(2)$ & $48.07(9)$ \\
\hline $\mathrm{C}(12)-\mathrm{Th}(1)-\mathrm{C}(2)$ & $156.32(9)$ \\
\hline $\mathrm{C}(4)-\mathrm{Th}(1)-\mathrm{C}(2)$ & $48.18(9)$ \\
\hline $\mathrm{C}(15)-\mathrm{Th}(1)-\mathrm{C}(2)$ & $128.02(9)$ \\
\hline $\mathrm{C}(11)-\mathrm{Th}(1)-\mathrm{C}(2)$ & $133.37(9)$ \\
\hline $\mathrm{C}(32)-\mathrm{N}(1)-\mathrm{C}(28)$ & $126.1(3)$ \\
\hline $\mathrm{C}(32)-\mathrm{N}(1)-\mathrm{O}(1)$ & $118.5(3)$ \\
\hline $\mathrm{C}(28)-\mathrm{N}(1)-\mathrm{O}(1)$ & $115.3(3)$ \\
\hline $\mathrm{C}(32)-\mathrm{N}(1)-\mathrm{Th}(1)$ & $171.6(2)$ \\
\hline $\mathrm{C}(28)-\mathrm{N}(1)-\mathrm{Th}(1)$ & $61.99(17)$ \\
\hline $\mathrm{O}(1)-\mathrm{N}(1)-\mathrm{Th}(1)$ & $53.35(13)$ \\
\hline $\mathrm{N}(1)-\mathrm{O}(1)-\mathrm{Th}(1)$ & $99.81(16)$ \\
\hline $\mathrm{C}(2)-\mathrm{C}(1)-\mathrm{C}(5)$ & 108.1(3) \\
\hline $\mathrm{C}(2)-\mathrm{C}(1)-\mathrm{C}(6)$ & $127.9(3)$ \\
\hline$C(5)-C(1)-C(6)$ & $123.8(3)$ \\
\hline $\mathrm{C}(2)-\mathrm{C}(1)-\mathrm{Th}(1)$ & $76.57(17)$ \\
\hline $\mathrm{C}(5)-\mathrm{C}(1)-\mathrm{Th}(1)$ & $75.57(17)$ \\
\hline $\mathrm{C}(6)-\mathrm{C}(1)-\mathrm{Th}(1)$ & $118.7(2)$ \\
\hline$C(3)-C(2)-C(1)$ & $107.8(3)$ \\
\hline$C(3)-C(2)-C(7)$ & $125.8(3)$ \\
\hline $\mathrm{C}(1)-\mathrm{C}(2)-\mathrm{C}(7)$ & $126.2(3)$ \\
\hline
\end{tabular}




\begin{tabular}{|c|c|}
\hline $\mathrm{C}(3)-\mathrm{C}(2)-\mathrm{Th}(1)$ & $76.09(18)$ \\
\hline$C(1)-C(2)-T h(1)$ & $74.28(17)$ \\
\hline$C(7)-C(2)-\operatorname{Th}(1)$ & 119.2(2) \\
\hline $\mathrm{C}(2)-\mathrm{C}(3)-\mathrm{C}(4)$ & $108.6(3)$ \\
\hline $\mathrm{C}(2)-\mathrm{C}(3)-\mathrm{C}(8)$ & $125.1(3)$ \\
\hline $\mathrm{C}(4)-\mathrm{C}(3)-\mathrm{C}(8)$ & $125.5(3)$ \\
\hline $\mathrm{C}(2)-\mathrm{C}(3)-\mathrm{Th}(1)$ & $75.09(18)$ \\
\hline $\mathrm{C}(4)-\mathrm{C}(3)-\mathrm{Th}(1)$ & $74.32(17)$ \\
\hline $\mathrm{C}(8)-\mathrm{C}(3)-\mathrm{Th}(1)$ & $124.7(2)$ \\
\hline$C(5)-C(4)-C(3)$ & 107.2(3) \\
\hline$C(5)-C(4)-C(9)$ & $125.8(3)$ \\
\hline $\mathrm{C}(3)-\mathrm{C}(4)-\mathrm{C}(9)$ & $126.7(3)$ \\
\hline $\mathrm{C}(5)-\mathrm{C}(4)-\mathrm{Th}(1)$ & $75.05(17)$ \\
\hline $\mathrm{C}(3)-\mathrm{C}(4)-\mathrm{Th}(1)$ & $76.50(17)$ \\
\hline $\mathrm{C}(9)-\mathrm{C}(4)-\mathrm{Th}(1)$ & 119.2(2) \\
\hline$C(1)-C(5)-C(4)$ & $108.3(3)$ \\
\hline$C(1)-C(5)-C(10)$ & $124.2(3)$ \\
\hline $\mathrm{C}(4)-\mathrm{C}(5)-\mathrm{C}(10)$ & $126.9(3)$ \\
\hline $\mathrm{C}(1)-\mathrm{C}(5)-\mathrm{Th}(1)$ & $75.12(17)$ \\
\hline $\mathrm{C}(4)-\mathrm{C}(5)-\mathrm{Th}(1)$ & $75.68(17)$ \\
\hline $\mathrm{C}(10)-\mathrm{C}(5)-\mathrm{Th}(1)$ & $123.0(2)$ \\
\hline $\mathrm{C}(15)-\mathrm{C}(11)-\mathrm{C}(12)$ & $108.6(3)$ \\
\hline$C(15)-C(11)-C(16)$ & $126.3(3)$ \\
\hline $\mathrm{C}(12)-\mathrm{C}(11)-\mathrm{C}(16)$ & $123.6(3)$ \\
\hline $\mathrm{C}(15)-\mathrm{C}(11)-\mathrm{Th}(1)$ & $75.35(18)$ \\
\hline $\mathrm{C}(12)-\mathrm{C}(11)-\mathrm{Th}(1)$ & $74.82(18)$ \\
\hline $\mathrm{C}(16)-\mathrm{C}(11)-\mathrm{Th}(1)$ & $127.0(2)$ \\
\hline $\mathrm{C}(13)-\mathrm{C}(12)-\mathrm{C}(11)$ & 107.2(3) \\
\hline $\mathrm{C}(13)-\mathrm{C}(12)-\mathrm{C}(17)$ & $127.7(3)$ \\
\hline$C(11)-C(12)-C(17)$ & $124.6(3)$ \\
\hline $\mathrm{C}(13)-\mathrm{C}(12)-\mathrm{Th}(1)$ & $74.97(18)$ \\
\hline $\mathrm{C}(11)-\mathrm{C}(12)-\mathrm{Th}(1)$ & $75.99(18)$ \\
\hline $\mathrm{C}(17)-\mathrm{C}(12)-\mathrm{Th}(1)$ & $120.9(2)$ \\
\hline$C(12)-C(13)-C(14)$ & $108.3(3)$ \\
\hline$C(12)-C(13)-C(18)$ & $126.5(3)$ \\
\hline C(14)-C(13)-C(18) & $125.0(3)$ \\
\hline
\end{tabular}




$\begin{array}{lc}\mathrm{C}(12)-\mathrm{C}(13)-\mathrm{Th}(1) & 75.84(18) \\ \mathrm{C}(14)-\mathrm{C}(13)-\mathrm{Th}(1) & 75.42(18) \\ \mathrm{C}(18)-\mathrm{C}(13)-\mathrm{Th}(1) & 118.4(2) \\ \mathrm{C}(15)-\mathrm{C}(14)-\mathrm{C}(13) & 108.2(3) \\ \mathrm{C}(15)-\mathrm{C}(14)-\mathrm{C}(19) & 127.1(3) \\ \mathrm{C}(13)-\mathrm{C}(14)-\mathrm{C}(19) & 124.2(3) \\ \mathrm{C}(15)-\mathrm{C}(14)-\mathrm{Th}(1) & 76.27(19) \\ \mathrm{C}(13)-\mathrm{C}(14)-\mathrm{Th}(1) & 75.30(18) \\ \mathrm{C}(19)-\mathrm{C}(14)-\mathrm{Th}(1) & 121.1(2) \\ \mathrm{C}(14)-\mathrm{C}(15)-\mathrm{C}(11) & 107.7(3) \\ \mathrm{C}(14)-\mathrm{C}(15)-\mathrm{C}(20) & 126.3(3) \\ \mathrm{C}(11)-\mathrm{C}(15)-\mathrm{C}(20) & 125.9(3) \\ \mathrm{C}(14)-\mathrm{C}(15)-\mathrm{Th}(1) & 74.70(18) \\ \mathrm{C}(11)-\mathrm{C}(15)-\mathrm{Th}(1) & 75.71(18) \\ \mathrm{C}(20)-\mathrm{C}(15)-\mathrm{Th}(1) & 118.7(2) \\ \mathrm{C}(22)-\mathrm{C}(21)-\mathrm{Th}(1) & 128.1(2) \\ \mathrm{C}(23)-\mathrm{C}(22)-\mathrm{C}(27) & 116.8(3) \\ \mathrm{C}(23)-\mathrm{C}(22)-\mathrm{C}(21) & 122.3(3) \\ \mathrm{C}(27)-\mathrm{C}(22)-\mathrm{C}(21) & 120.9(3) \\ \mathrm{C}(24)-\mathrm{C}(23)-\mathrm{C}(22) & 122.0(4) \\ \mathrm{C}(23)-\mathrm{C}(24)-\mathrm{C}(25) & 120.7(4) \\ \mathrm{C}(26)-\mathrm{C}(25)-\mathrm{C}(24) & 118.2(4) \\ \mathrm{C}(27)-\mathrm{C}(26)-\mathrm{C}(25) & 120.7(4) \\ \mathrm{C}(26)-\mathrm{C}(27)-\mathrm{C}(22) & 121.6(4) \\ \mathrm{N}(1)-\mathrm{C}(28)-\mathrm{C}(29) & 113.3(3) \\ \mathrm{N}(1)-\mathrm{C}(28)-\mathrm{Th}(1) & 90.9(2) \\ \mathrm{C}(29)-\mathrm{C}(28)-\mathrm{Th}(1) & 155.8(2) \\ \mathrm{C}(30)-\mathrm{C}(29)-\mathrm{C}(28) & 123.0(3) \\ \mathrm{C}(31)-\mathrm{C}(30)-\mathrm{C}(29) & 118.9(3) \\ \mathrm{C}(32)-\mathrm{C}(31)-\mathrm{C}(30) & 119.7(4) \\ \mathrm{N}(1)-\mathrm{C}(32)-\mathrm{C}(31) & 118.8(4) \\ & \end{array}$

Crystallographic Details for Complex 5a. A concentrated diethyl ether solution of 5a was cooled to $-35^{\circ} \mathrm{C}$. After a few days, yellow crystals were formed. A crystal was chosen and 
mounted from Paratone $\mathrm{N}$ oil onto a glass fiber under argon gas flow and placed on a Bruker P4/CCD diffractometer, equipped with a Bruker LT-2 temperature device. Data collection and initial indexing and cell refinement were handled using SMART software. ${ }^{1}$ Frame integration and final cell parameter calculations were carried out using SAINT software. ${ }^{2}$ The data were corrected for absorption using the SADABS program. ${ }^{3}$ Structure solution, refinement, graphics, and creation of publication materials were performed using SHELXTL. ${ }^{4}$ The structure was solved using direct methods, completed by subsequent difference Fourier techniques, and refined by full-matrix least-squares procedures. Full details of crystal data and structure refinement of 5a (Figure S3) are shown in Tables S5 and S6:

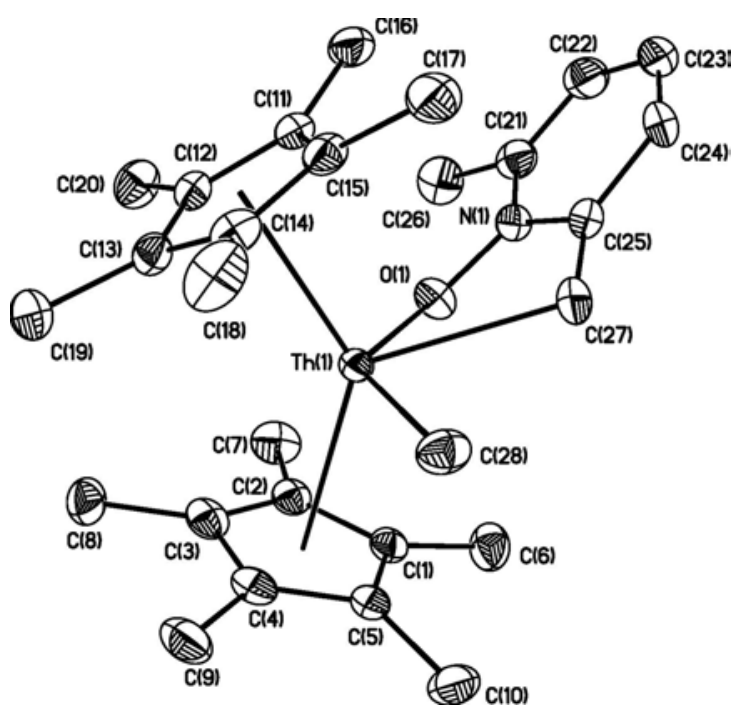

Figure S3. ORTEP diagram of Complex 5a.

Table S5. Crystal data and structure refinement for Complex 5a.

Empirical formula

Formula weight

Temperature

Wavelength
C28 H41 N O Th

639.66

203(2) K

$0.71073 \AA$ 


$\begin{array}{ll}\text { Crystal system } & \text { monoclinic } \\ \text { Space group } & \mathrm{P} 2 / \mathrm{n} \\ \text { Unit cell dimensions } & \mathrm{a}=12.379(3) \AA \\ & \mathrm{b}=15.315(3) \AA \beta=91.050(4)^{\circ} . \\ & \mathrm{c}=13.674(3) \AA \\ \text { Volume } & 2592.0(10) \AA^{3} \\ Z & 4 \\ \text { Density (calculated) } & 1.639 \mathrm{Mg} / \mathrm{m}^{3} \\ \text { Absorption coefficient } & 5.772 \mathrm{~mm}-1 \\ \text { F(000) } & 1256 \\ \text { Crystal size } & 0.32 \times 0.22 \times 0.08 \mathrm{~mm}{ }^{3} \\ \text { Theta range for data collection } & 2.00 \text { to } 27.90^{\circ} . \\ \text { Index ranges } & -12<=\mathrm{h}<=15,-20<=\mathrm{k}<=20,-17<=1<=17 \\ \text { Reflections collected } & 17421 \\ \text { Independent reflections } & 5636[\mathrm{R}(\text { int })=0.0189] \\ \text { Max. and min. transmission } & 0.6553 \text { and } 0.2596 \\ \text { Refinement method } & \text { Full-matrix least-squares on } \mathrm{F}^{2} \\ \text { Data / restraints / parameters } & 5636 / 0 / 286 \\ \text { Goodness-of-fit on F } 2 & 1.462 \\ \text { Final R indices [I }>2 \text { sigma(I) } & \mathrm{R} 1=0.0282, \mathrm{wR} 2=0.0789 \\ \text { R indices (all data) } & \mathrm{R} 1=0.0387, \mathrm{wR} 2=0.0846 \\ \text { Largest diff. peak and hole } & 2.345 \text { and }-0.959 \mathrm{e} . \AA^{-3} \\ & \end{array}$

\section{Table S6. Bond lengths $(\AA)$ and angles $\left({ }^{\circ}\right)$ for Complex 5 a.}

$\begin{array}{ll}\operatorname{Th}(1)-\mathrm{O}(1) & 2.424(3) \\ \operatorname{Th}(1)-\mathrm{C}(28) & 2.496(5) \\ \operatorname{Th}(1)-\mathrm{C}(27) & 2.641(5) \\ \operatorname{Th}(1)-\mathrm{C}(12) & 2.792(4) \\ \operatorname{Th}(1)-\mathrm{C}(13) & 2.810(4) \\ \operatorname{Th}(1)-\mathrm{C}(11) & 2.811(4) \\ \operatorname{Th}(1)-\mathrm{C}(15) & 2.826(4) \\ \operatorname{Th}(1)-\mathrm{C}(14) & 2.825(4) \\ \operatorname{Th}(1)-\mathrm{C}(1) & 2.833(4)\end{array}$




\begin{tabular}{|c|c|}
\hline $\operatorname{Th}(1)-\mathrm{C}(2)$ & $2.841(4)$ \\
\hline $\operatorname{Th}(1)-\mathrm{C}(4)$ & $2.846(5)$ \\
\hline $\operatorname{Th}(1)-\mathrm{C}(5)$ & $2.848(4)$ \\
\hline $\operatorname{Th}(1)-\mathrm{C}(3)$ & $2.852(4)$ \\
\hline $\operatorname{Th}(1)-H(27 A)$ & $3.34(7)$ \\
\hline $\operatorname{Th}(1)-H(27 B)$ & $2.63(7)$ \\
\hline $\mathrm{O}(1)-\mathrm{N}(1)$ & $1.359(5)$ \\
\hline$C(1)-C(2)$ & $1.414(6)$ \\
\hline$C(1)-C(5)$ & $1.413(7)$ \\
\hline$C(1)-C(6)$ & $1.508(7)$ \\
\hline$C(2)-C(3)$ & $1.407(7)$ \\
\hline$C(2)-C(7)$ & $1.506(7)$ \\
\hline$C(3)-C(4)$ & $1.440(7)$ \\
\hline$C(3)-C(8)$ & $1.509(7)$ \\
\hline$C(4)-C(5)$ & $1.417(7)$ \\
\hline$C(4)-C(9)$ & $1.500(8)$ \\
\hline$C(5)-C(10)$ & $1.494(6)$ \\
\hline $\mathrm{C}(11)-\mathrm{C}(12)$ & $1.408(6)$ \\
\hline$C(11)-C(15)$ & $1.417(6)$ \\
\hline$C(11)-C(16)$ & $1.506(6)$ \\
\hline$C(12)-C(13)$ & $1.438(6)$ \\
\hline$C(12)-C(20)$ & $1.490(6)$ \\
\hline$C(13)-C(14)$ & $1.410(6)$ \\
\hline$C(13)-C(19)$ & $1.509(6)$ \\
\hline$C(14)-C(15)$ & $1.398(7)$ \\
\hline $\mathrm{C}(14)-\mathrm{C}(18)$ & $1.506(7)$ \\
\hline$C(15)-C(17)$ & $1.500(6)$ \\
\hline $\mathrm{N}(1)-\mathrm{C}(21)$ & $1.356(6)$ \\
\hline $\mathrm{N}(1)-\mathrm{C}(25)$ & $1.375(6)$ \\
\hline $\mathrm{C}(21)-\mathrm{C}(22)$ & $1.366(7)$ \\
\hline$C(21)-C(26)$ & $1.494(7)$ \\
\hline$C(22)-C(23)$ & $1.405(8)$ \\
\hline$C(23)-C(24)$ & $1.360(8)$ \\
\hline$C(24)-C(25)$ & $1.433(7)$ \\
\hline$C(25)-C(27)$ & $1.395(7)$ \\
\hline
\end{tabular}




\begin{tabular}{|c|c|}
\hline $\mathrm{O}(1)-\mathrm{Th}(1)-\mathrm{C}(28)$ & $133.84(16)$ \\
\hline $\mathrm{O}(1)-\mathrm{Th}(1)-\mathrm{C}(27)$ & $61.80(14)$ \\
\hline $\mathrm{C}(28)-\mathrm{Th}(1)-\mathrm{C}(27)$ & $74.38(18)$ \\
\hline $\mathrm{O}(1)-\mathrm{Th}(1)-\mathrm{C}(12)$ & $90.10(12)$ \\
\hline $\mathrm{C}(28)-\mathrm{Th}(1)-\mathrm{C}(12)$ & $123.83(15)$ \\
\hline $\mathrm{C}(27)-\mathrm{Th}(1)-\mathrm{C}(12)$ & $116.57(15)$ \\
\hline $\mathrm{O}(1)-\operatorname{Th}(1)-\mathrm{C}(13)$ & $119.76(12)$ \\
\hline $\mathrm{C}(28)-\mathrm{Th}(1)-\mathrm{C}(13)$ & $98.96(16)$ \\
\hline $\mathrm{C}(27)-\mathrm{Th}(1)-\mathrm{C}(13)$ & $130.35(15)$ \\
\hline $\mathrm{C}(12)-\mathrm{Th}(1)-\mathrm{C}(13)$ & $29.74(13)$ \\
\hline $\mathrm{O}(1)-\mathrm{Th}(1)-\mathrm{C}(11)$ & $81.24(12)$ \\
\hline $\mathrm{C}(28)-\mathrm{Th}(1)-\mathrm{C}(11)$ & $112.47(15)$ \\
\hline $\mathrm{C}(27)-\mathrm{Th}(1)-\mathrm{C}(11)$ & $88.14(15)$ \\
\hline $\mathrm{C}(12)-\mathrm{Th}(1)-\mathrm{C}(11)$ & $29.11(12)$ \\
\hline $\mathrm{C}(13)-\mathrm{Th}(1)-\mathrm{C}(11)$ & $48.17(13)$ \\
\hline $\mathrm{O}(1)-\mathrm{Th}(1)-\mathrm{C}(15)$ & $103.63(13)$ \\
\hline $\mathrm{C}(28)-\mathrm{Th}(1)-\mathrm{C}(15)$ & $83.49(15)$ \\
\hline $\mathrm{C}(27)-\mathrm{Th}(1)-\mathrm{C}(15)$ & $82.70(16)$ \\
\hline $\mathrm{C}(12)-\mathrm{Th}(1)-\mathrm{C}(15)$ & $48.07(12)$ \\
\hline $\mathrm{C}(13)-\mathrm{Th}(1)-\mathrm{C}(15)$ & $47.75(13)$ \\
\hline $\mathrm{C}(11)-\mathrm{Th}(1)-\mathrm{C}(15)$ & $29.12(13)$ \\
\hline $\mathrm{O}(1)-\mathrm{Th}(1)-\mathrm{C}(14)$ & $128.88(13)$ \\
\hline $\mathrm{C}(28)-\mathrm{Th}(1)-\mathrm{C}(14)$ & $75.61(15)$ \\
\hline$C(27)-\operatorname{Th}(1)-C(14)$ & $106.62(16)$ \\
\hline $\mathrm{C}(12)-\mathrm{Th}(1)-\mathrm{C}(14)$ & $48.23(13)$ \\
\hline $\mathrm{C}(13)-\mathrm{Th}(1)-\mathrm{C}(14)$ & $28.98(13)$ \\
\hline $\mathrm{C}(11)-\mathrm{Th}(1)-\mathrm{C}(14)$ & $47.76(13)$ \\
\hline $\mathrm{C}(15)-\mathrm{Th}(1)-\mathrm{C}(14)$ & $28.64(14)$ \\
\hline $\mathrm{O}(1)-\mathrm{Th}(1)-\mathrm{C}(1)$ & $72.47(13)$ \\
\hline $\mathrm{C}(28)-\mathrm{Th}(1)-\mathrm{C}(1)$ & $99.40(15)$ \\
\hline $\mathrm{C}(27)-\operatorname{Th}(1)-\mathrm{C}(1)$ & $95.50(15)$ \\
\hline $\mathrm{C}(12)-\operatorname{Th}(1)-\mathrm{C}(1)$ & $130.70(12)$ \\
\hline $\mathrm{C}(13)-\operatorname{Th}(1)-\mathrm{C}(1)$ & $133.73(13)$ \\
\hline$C(11)-\operatorname{Th}(1)-C(1)$ & $147.66(13)$ \\
\hline $\mathrm{C}(15)-\operatorname{Th}(1)-\mathrm{C}(1)$ & $176.08(14)$ \\
\hline $\mathrm{C}(14)-\mathrm{Th}(1)-\mathrm{C}(1)$ & $154.70(14)$ \\
\hline
\end{tabular}




\begin{tabular}{|c|c|}
\hline $\mathrm{O}(1)-\mathrm{Th}(1)-\mathrm{C}(2)$ & $70.63(13)$ \\
\hline $\mathrm{C}(28)-\mathrm{Th}(1)-\mathrm{C}(2)$ & $122.31(15)$ \\
\hline $\mathrm{C}(27)-\operatorname{Th}(1)-\mathrm{C}(2)$ & $116.74(16)$ \\
\hline $\mathrm{C}(12)-\operatorname{Th}(1)-\mathrm{C}(2)$ & $102.02(12)$ \\
\hline $\mathrm{C}(13)-\operatorname{Th}(1)-\mathrm{C}(2)$ & $108.28(13)$ \\
\hline $\mathrm{C}(11)-\operatorname{Th}(1)-\mathrm{C}(2)$ & $123.75(13)$ \\
\hline$C(15)-\operatorname{Th}(1)-C(2)$ & $150.07(12)$ \\
\hline $\mathrm{C}(14)-\mathrm{Th}(1)-\mathrm{C}(2)$ & $135.94(14)$ \\
\hline $\mathrm{C}(1)-\mathrm{Th}(1)-\mathrm{C}(2)$ & $28.85(12)$ \\
\hline $\mathrm{O}(1)-\mathrm{Th}(1)-\mathrm{C}(4)$ & $116.68(13)$ \\
\hline $\mathrm{C}(28)-\mathrm{Th}(1)-\mathrm{C}(4)$ & $81.27(16)$ \\
\hline $\mathrm{C}(27)-\mathrm{Th}(1)-\mathrm{C}(4)$ & $131.20(16)$ \\
\hline $\mathrm{C}(12)-\mathrm{Th}(1)-\mathrm{C}(4)$ & $112.16(14)$ \\
\hline $\mathrm{C}(13)-\mathrm{Th}(1)-\mathrm{C}(4)$ & $94.45(14)$ \\
\hline $\mathrm{C}(11)-\mathrm{Th}(1)-\mathrm{C}(4)$ & $140.57(14)$ \\
\hline $\mathrm{C}(15)-\mathrm{Th}(1)-\mathrm{C}(4)$ & $135.91(14)$ \\
\hline $\mathrm{C}(14)-\mathrm{Th}(1)-\mathrm{C}(4)$ & $107.28(15)$ \\
\hline $\mathrm{C}(1)-\mathrm{Th}(1)-\mathrm{C}(4)$ & $47.57(14)$ \\
\hline $\mathrm{C}(2)-\mathrm{Th}(1)-\mathrm{C}(4)$ & $47.58(14)$ \\
\hline $\mathrm{O}(1)-\mathrm{Th}(1)-\mathrm{C}(5)$ & $100.40(13)$ \\
\hline $\mathrm{C}(28)-\mathrm{Th}(1)-\mathrm{C}(5)$ & $74.98(15)$ \\
\hline $\mathrm{C}(27)-\mathrm{Th}(1)-\mathrm{C}(5)$ & $103.06(15)$ \\
\hline $\mathrm{C}(12)-\mathrm{Th}(1)-\mathrm{C}(5)$ & $139.08(13)$ \\
\hline $\mathrm{C}(13)-\mathrm{Th}(1)-\mathrm{C}(5)$ & $123.02(13)$ \\
\hline $\mathrm{C}(11)-\operatorname{Th}(1)-\mathrm{C}(5)$ & $168.12(13)$ \\
\hline$C(15)-\operatorname{Th}(1)-C(5)$ & $155.04(14)$ \\
\hline $\mathrm{C}(14)-\operatorname{Th}(1)-\mathrm{C}(5)$ & $130.09(14)$ \\
\hline $\mathrm{C}(1)-\operatorname{Th}(1)-\mathrm{C}(5)$ & $28.80(13)$ \\
\hline $\mathrm{C}(2)-\mathrm{Th}(1)-\mathrm{C}(5)$ & $47.45(13)$ \\
\hline $\mathrm{C}(4)-\mathrm{Th}(1)-\mathrm{C}(5)$ & $28.81(14)$ \\
\hline $\mathrm{O}(1)-\mathrm{Th}(1)-\mathrm{C}(3)$ & $97.23(13)$ \\
\hline $\mathrm{C}(28)-\operatorname{Th}(1)-\mathrm{C}(3)$ & $110.29(16)$ \\
\hline $\mathrm{C}(27)-\operatorname{Th}(1)-\mathrm{C}(3)$ & $142.88(16)$ \\
\hline $\mathrm{C}(12)-\operatorname{Th}(1)-\mathrm{C}(3)$ & $91.97(13)$ \\
\hline $\mathrm{C}(13)-\operatorname{Th}(1)-\mathrm{C}(3)$ & $86.22(14)$ \\
\hline $\mathrm{C}(11)-\mathrm{Th}(1)-\mathrm{C}(3)$ & $120.46(13)$ \\
\hline
\end{tabular}




\begin{tabular}{|c|c|}
\hline $\mathrm{C}(15)-\mathrm{Th}(1)-\mathrm{C}(3)$ & $133.91(14)$ \\
\hline$C(14)-T h(1)-C(3)$ & $110.19(14)$ \\
\hline $\mathrm{C}(1)-\mathrm{Th}(1)-\mathrm{C}(3)$ & $47.56(13)$ \\
\hline $\mathrm{C}(2)-\mathrm{Th}(1)-\mathrm{C}(3)$ & $28.62(14)$ \\
\hline $\mathrm{C}(4)-\mathrm{Th}(1)-\mathrm{C}(3)$ & $29.28(14)$ \\
\hline $\mathrm{C}(5)-\mathrm{Th}(1)-\mathrm{C}(3)$ & $47.72(13)$ \\
\hline $\mathrm{O}(1)-\mathrm{Th}(1)-\mathrm{H}(27 \mathrm{~A})$ & $77.5(12)$ \\
\hline $\mathrm{C}(28)-\mathrm{Th}(1)-\mathrm{H}(27 \mathrm{~A})$ & $59.4(12)$ \\
\hline $\mathrm{C}(27)-\mathrm{Th}(1)-\mathrm{H}(27 \mathrm{~A})$ & $15.6(12)$ \\
\hline $\mathrm{C}(12)-\mathrm{Th}(1)-\mathrm{H}(27 \mathrm{~A})$ & $119.4(13)$ \\
\hline $\mathrm{C}(13)-\mathrm{Th}(1)-\mathrm{H}(27 \mathrm{~A})$ & $124.2(13)$ \\
\hline $\mathrm{C}(11)-\mathrm{Th}(1)-\mathrm{H}(27 \mathrm{~A})$ & $90.4(13)$ \\
\hline $\mathrm{C}(15)-\mathrm{Th}(1)-\mathrm{H}(27 \mathrm{~A})$ & $77.5(13)$ \\
\hline $\mathrm{C}(14)-\mathrm{Th}(1)-\mathrm{H}(27 \mathrm{~A})$ & $97.0(13)$ \\
\hline C(1)-Th(1)-H(27A) & $101.6(13)$ \\
\hline $\mathrm{C}(2)-\mathrm{Th}(1)-\mathrm{H}(27 \mathrm{~A})$ & $127.0(13)$ \\
\hline $\mathrm{C}(4)-\mathrm{Th}(1)-\mathrm{H}(27 \mathrm{~A})$ & $126.5(13)$ \\
\hline $\mathrm{C}(5)-\mathrm{Th}(1)-\mathrm{H}(27 \mathrm{~A})$ & $101.5(13)$ \\
\hline $\mathrm{C}(3)-\mathrm{Th}(1)-\mathrm{H}(27 \mathrm{~A})$ & $147.8(13)$ \\
\hline $\mathrm{O}(1)-\mathrm{Th}(1)-\mathrm{H}(27 \mathrm{~B})$ & $60.1(15)$ \\
\hline $\mathrm{C}(28)-\mathrm{Th}(1)-\mathrm{H}(27 \mathrm{~B})$ & $73.9(16)$ \\
\hline $\mathrm{C}(27)-\mathrm{Th}(1)-\mathrm{H}(27 \mathrm{~B})$ & $22.6(16)$ \\
\hline $\mathrm{C}(12)-\mathrm{Th}(1)-\mathrm{H}(27 \mathrm{~B})$ & $136.2(15)$ \\
\hline $\mathrm{C}(13)-\mathrm{Th}(1)-\mathrm{H}(27 \mathrm{~B})$ & $152.8(17)$ \\
\hline C(11)-Th(1)-H(27B) & $109.4(16)$ \\
\hline $\mathrm{C}(15)-\mathrm{Th}(1)-\mathrm{H}(27 \mathrm{~B})$ & $105.0(17)$ \\
\hline $\mathrm{C}(14)-\mathrm{Th}(1)-\mathrm{H}(27 \mathrm{~B})$ & $126.7(17)$ \\
\hline $\mathrm{C}(1)-\mathrm{Th}(1)-\mathrm{H}(27 \mathrm{~B})$ & $73.4(17)$ \\
\hline $\mathrm{C}(2)-\mathrm{Th}(1)-\mathrm{H}(27 \mathrm{~B})$ & $97.3(17)$ \\
\hline $\mathrm{C}(4)-\mathrm{Th}(1)-\mathrm{H}(27 \mathrm{~B})$ & $109.9(16)$ \\
\hline $\mathrm{C}(5)-\mathrm{Th}(1)-\mathrm{H}(27 \mathrm{~B})$ & $81.2(16)$ \\
\hline $\mathrm{C}(3)-\mathrm{Th}(1)-\mathrm{H}(27 \mathrm{~B})$ & $121.0(17)$ \\
\hline $\mathrm{H}(27 \mathrm{~A})-\mathrm{Th}(1)-\mathrm{H}(27 \mathrm{~B})$ & $30(2)$ \\
\hline $\mathrm{N}(1)-\mathrm{O}(1)-\mathrm{Th}(1)$ & $120.1(3)$ \\
\hline$C(2)-C(1)-C(5)$ & $108.2(4)$ \\
\hline$C(2)-C(1)-C(6)$ & $125.6(5)$ \\
\hline
\end{tabular}




\begin{tabular}{|c|c|}
\hline$C(5)-C(1)-C(6)$ & $126.0(4)$ \\
\hline $\mathrm{C}(2)-\mathrm{C}(1)-\mathrm{Th}(1)$ & $75.9(2)$ \\
\hline $\mathrm{C}(5)-\mathrm{C}(1)-\mathrm{Th}(1)$ & $76.2(2)$ \\
\hline $\mathrm{C}(6)-\mathrm{C}(1)-\mathrm{Th}(1)$ & $118.6(3)$ \\
\hline$C(3)-C(2)-C(1)$ & $108.7(4)$ \\
\hline$C(3)-C(2)-C(7)$ & $124.7(4)$ \\
\hline $\mathrm{C}(1)-\mathrm{C}(2)-\mathrm{C}(7)$ & $126.4(5)$ \\
\hline $\mathrm{C}(3)-\mathrm{C}(2)-\mathrm{Th}(1)$ & $76.1(3)$ \\
\hline $\mathrm{C}(1)-\mathrm{C}(2)-\mathrm{Th}(1)$ & $75.3(2)$ \\
\hline$C(7)-C(2)-T h(1)$ & $118.7(3)$ \\
\hline $\mathrm{C}(2)-\mathrm{C}(3)-\mathrm{C}(4)$ & $107.3(4)$ \\
\hline $\mathrm{C}(2)-\mathrm{C}(3)-\mathrm{C}(8)$ & $125.9(5)$ \\
\hline $\mathrm{C}(4)-\mathrm{C}(3)-\mathrm{C}(8)$ & $125.4(5)$ \\
\hline $\mathrm{C}(2)-\mathrm{C}(3)-\mathrm{Th}(1)$ & $75.3(3)$ \\
\hline $\mathrm{C}(4)-\mathrm{C}(3)-\mathrm{Th}(1)$ & $75.1(3)$ \\
\hline $\mathrm{C}(8)-\mathrm{C}(3)-\mathrm{Th}(1)$ & $126.0(3)$ \\
\hline$C(5)-C(4)-C(3)$ & $107.7(4)$ \\
\hline$C(5)-C(4)-C(9)$ & $126.6(5)$ \\
\hline $\mathrm{C}(3)-\mathrm{C}(4)-\mathrm{C}(9)$ & $125.6(5)$ \\
\hline $\mathrm{C}(5)-\mathrm{C}(4)-\mathrm{Th}(1)$ & $75.7(3)$ \\
\hline $\mathrm{C}(3)-\mathrm{C}(4)-\mathrm{Th}(1)$ & $75.6(3)$ \\
\hline $\mathrm{C}(9)-\mathrm{C}(4)-\mathrm{Th}(1)$ & $118.3(3)$ \\
\hline$C(1)-C(5)-C(4)$ & $108.1(4)$ \\
\hline$C(1)-C(5)-C(10)$ & $125.2(5)$ \\
\hline $\mathrm{C}(4)-\mathrm{C}(5)-\mathrm{C}(10)$ & $126.0(5)$ \\
\hline $\mathrm{C}(1)-\mathrm{C}(5)-\mathrm{Th}(1)$ & $75.0(2)$ \\
\hline $\mathrm{C}(4)-\mathrm{C}(5)-\mathrm{Th}(1)$ & $75.5(3)$ \\
\hline$C(10)-C(5)-T h(1)$ & $122.9(3)$ \\
\hline$C(12)-C(11)-C(15)$ & $108.2(4)$ \\
\hline$C(12)-C(11)-C(16)$ & $125.3(4)$ \\
\hline$C(15)-C(11)-C(16)$ & $126.0(4)$ \\
\hline $\mathrm{C}(12)-\mathrm{C}(11)-\mathrm{Th}(1)$ & $74.7(2)$ \\
\hline $\mathrm{C}(15)-\mathrm{C}(11)-\mathrm{Th}(1)$ & $76.0(2)$ \\
\hline $\mathrm{C}(16)-\mathrm{C}(11)-\mathrm{Th}(1)$ & $122.0(3)$ \\
\hline$C(11)-C(12)-C(13)$ & $107.4(4)$ \\
\hline$C(11)-C(12)-C(20)$ & $125.6(4)$ \\
\hline
\end{tabular}




\begin{tabular}{|c|c|}
\hline $\mathrm{C}(13)-\mathrm{C}(12)-\mathrm{C}(20)$ & $126.9(4)$ \\
\hline $\mathrm{C}(11)-\mathrm{C}(12)-\mathrm{Th}(1)$ & $76.2(2)$ \\
\hline $\mathrm{C}(13)-\mathrm{C}(12)-\mathrm{Th}(1)$ & $75.8(2)$ \\
\hline $\mathrm{C}(20)-\mathrm{C}(12)-\mathrm{Th}(1)$ & $117.2(3)$ \\
\hline$C(14)-C(13)-C(12)$ & $107.4(4)$ \\
\hline$C(14)-C(13)-C(19)$ & $125.5(4)$ \\
\hline$C(12)-C(13)-C(19)$ & $126.1(4)$ \\
\hline $\mathrm{C}(14)-\mathrm{C}(13)-\mathrm{Th}(1)$ & $76.1(3)$ \\
\hline $\mathrm{C}(12)-\mathrm{C}(13)-\mathrm{Th}(1)$ & $74.5(2)$ \\
\hline C(19)-C(13)-Th(1) & $124.3(3)$ \\
\hline$C(15)-C(14)-C(13)$ & $108.7(4)$ \\
\hline$C(15)-C(14)-C(18)$ & $127.5(5)$ \\
\hline$C(13)-C(14)-C(18)$ & $123.2(5)$ \\
\hline $\mathrm{C}(15)-\mathrm{C}(14)-\mathrm{Th}(1)$ & $75.7(3)$ \\
\hline $\mathrm{C}(13)-\mathrm{C}(14)-\mathrm{Th}(1)$ & $74.9(3)$ \\
\hline $\mathrm{C}(18)-\mathrm{C}(14)-\mathrm{Th}(1)$ & $122.8(3)$ \\
\hline$C(14)-C(15)-C(11)$ & $108.3(4)$ \\
\hline$C(14)-C(15)-C(17)$ & $125.9(5)$ \\
\hline$C(11)-C(15)-C(17)$ & $125.7(5)$ \\
\hline $\mathrm{C}(14)-\mathrm{C}(15)-\mathrm{Th}(1)$ & $75.7(2)$ \\
\hline $\mathrm{C}(11)-\mathrm{C}(15)-\mathrm{Th}(1)$ & $74.8(2)$ \\
\hline $\mathrm{C}(17)-\mathrm{C}(15)-\mathrm{Th}(1)$ & 119.1(3) \\
\hline $\mathrm{C}(21)-\mathrm{N}(1)-\mathrm{O}(1)$ & $118.6(4)$ \\
\hline $\mathrm{C}(21)-\mathrm{N}(1)-\mathrm{C}(25)$ & $125.6(4)$ \\
\hline $\mathrm{O}(1)-\mathrm{N}(1)-\mathrm{C}(25)$ & $115.8(4)$ \\
\hline $\mathrm{N}(1)-\mathrm{C}(21)-\mathrm{C}(22)$ & $118.3(5)$ \\
\hline $\mathrm{N}(1)-\mathrm{C}(21)-\mathrm{C}(26)$ & $117.0(4)$ \\
\hline$C(22)-C(21)-C(26)$ & $124.6(5)$ \\
\hline$C(21)-C(22)-C(23)$ & $119.9(5)$ \\
\hline $\mathrm{C}(24)-\mathrm{C}(23)-\mathrm{C}(22)$ & $120.3(5)$ \\
\hline$C(23)-C(24)-C(25)$ & $121.0(5)$ \\
\hline $\mathrm{N}(1)-\mathrm{C}(25)-\mathrm{C}(27)$ & $117.3(4)$ \\
\hline $\mathrm{N}(1)-\mathrm{C}(25)-\mathrm{C}(24)$ & $114.5(5)$ \\
\hline $\mathrm{C}(27)-\mathrm{C}(25)-\mathrm{C}(24)$ & $127.9(5)$ \\
\hline $\mathrm{C}(25)-\mathrm{C}(27)-\mathrm{Th}(1)$ & $110.5(3)$ \\
\hline
\end{tabular}


Crystallographic Details for Complex 5b. A concentrated diethyl ether solution of $\mathbf{5 b}$ was cooled to $-35^{\circ} \mathrm{C}$. After a few days, yellow crystals were formed. A crystal was chosen and mounted from Paratone $\mathrm{N}$ oil onto a glass fiber under argon gas flow and placed on a Bruker P4/CCD diffractometer, equipped with a Bruker LT-2 temperature device. Data collection and initial indexing and cell refinement were handled using SMART software. ${ }^{1}$ Frame integration and final cell parameter calculations were carried out using SAINT software. ${ }^{2}$ The data were corrected for absorption using the SADABS program. ${ }^{3}$ Structure solution, refinement, graphics, and creation of publication materials were performed using SHELXTL. ${ }^{4}$ The structure was solved using direct methods, completed by subsequent difference Fourier techniques, and refined by full-matrix least-squares procedures. The disordered phenyl group of the benzyl ligand was refined as two one-half occupancy rigid groups labeled C22-C27 and C22'-C27'. Full details of crystal data and structure refinement of $\mathbf{5 b}$ (Figure S4) are shown in Tables S7 and S8:

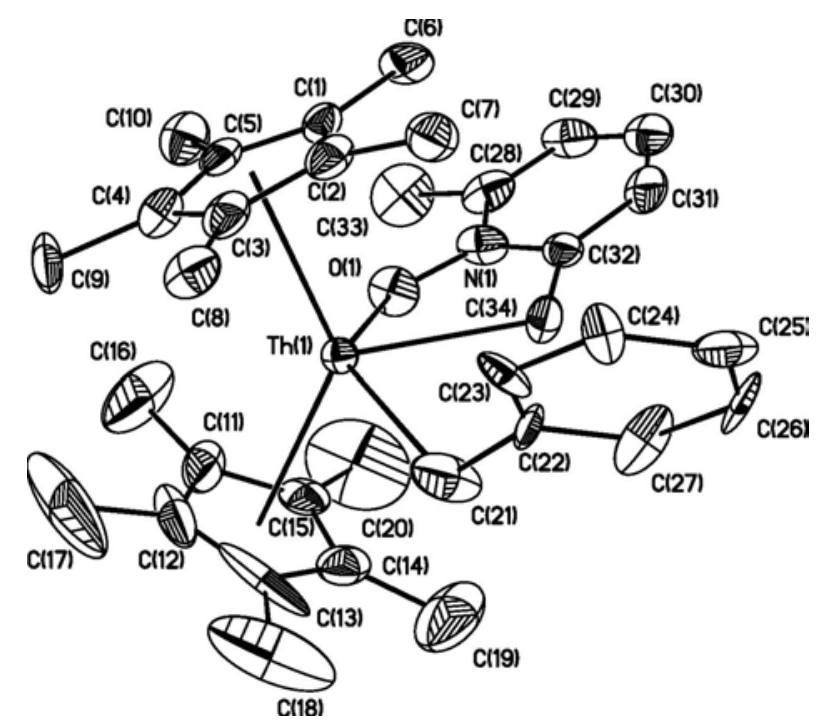

Figure S4. ORTEP diagram of Complex $\mathbf{5 b}$. 
Table S7. Crystal data and structure refinement for Complex 5 b.

\begin{tabular}{|c|c|c|}
\hline Empirical formula & \multicolumn{2}{|l|}{ C34 H45 N O Th } \\
\hline Formula weight & \multicolumn{2}{|l|}{715.75} \\
\hline Temperature & \multicolumn{2}{|l|}{ 293(2) K } \\
\hline Wavelength & \multicolumn{2}{|l|}{$0.71073 \AA$} \\
\hline Crystal system & \multicolumn{2}{|l|}{$\mathrm{P} 2_{1}$} \\
\hline Space group & \multicolumn{2}{|l|}{ monoclinic } \\
\hline \multirow[t]{3}{*}{ Unit cell dimensions } & $\mathrm{a}=9.812(2) \AA$ & $\alpha=90^{\circ}$ \\
\hline & $\mathrm{b}=15.279(3) \AA$ & $\beta=96.897(4)^{\circ}$. \\
\hline & $\mathrm{c}=10.093(2) \AA$ & $\gamma=90^{\circ}$ \\
\hline Volume & \multicolumn{2}{|l|}{$1502.2(6) \AA^{3}$} \\
\hline $\mathrm{Z}$ & \multicolumn{2}{|l|}{2} \\
\hline Density (calculated) & \multicolumn{2}{|l|}{$1.582 \mathrm{Mg} / \mathrm{m}^{3}$} \\
\hline Absorption coefficient & \multicolumn{2}{|l|}{$4.989 \mathrm{~mm}^{-1}$} \\
\hline $\mathrm{F}(000)$ & \multicolumn{2}{|l|}{708} \\
\hline Crystal size & \multicolumn{2}{|c|}{$0.24 \times 0.12 \times 0.12 \mathrm{~mm}^{3}$} \\
\hline Theta range for data collection & \multicolumn{2}{|l|}{2.03 to $28.01^{\circ}$} \\
\hline Index ranges & \multicolumn{2}{|c|}{$-10<=\mathrm{h}<=11,-20<=\mathrm{k}<=19,-13<=\mathrm{l}<=13$} \\
\hline Reflections collected & \multicolumn{2}{|l|}{9020} \\
\hline Independent reflections & \multicolumn{2}{|c|}{$5054[\mathrm{R}(\mathrm{int})=0.0259]$} \\
\hline Completeness to theta $=28.01^{\circ}$ & \multicolumn{2}{|l|}{$82.8 \%$} \\
\hline Max. and min. transmission & \multicolumn{2}{|l|}{0.5859 and 0.3806} \\
\hline Refinement method & \multicolumn{2}{|c|}{ Full-matrix least-squares on $\mathrm{F}^{2}$} \\
\hline Data / restraints / parameters & \multicolumn{2}{|l|}{$5054 / 1 / 277$} \\
\hline Goodness-of-fit on $\mathrm{F}^{2}$ & \multicolumn{2}{|l|}{1.156} \\
\hline Final $R$ indices $[\mathrm{I}>2 \operatorname{sigma}(\mathrm{I})]$ & \multicolumn{2}{|c|}{$\mathrm{R} 1=0.0528, \mathrm{wR} 2=0.1336$} \\
\hline $\mathrm{R}$ indices (all data) & \multicolumn{2}{|c|}{$\mathrm{R} 1=0.0614, \mathrm{wR} 2=0.1393$} \\
\hline Absolute structure parameter & \multicolumn{2}{|l|}{$0.08(2)$} \\
\hline Largest diff. peak and hole & \multicolumn{2}{|c|}{4.536 and -3.294 e. $\AA^{-3}$} \\
\hline
\end{tabular}

\section{Table S8. Bond lengths $(\AA)$ and angles $\left({ }^{\circ}\right)$ for Complex $5 b$.}

$\begin{array}{ll}\mathrm{N}(1)-\mathrm{C}(28) & 1.34(2) \\ \mathrm{N}(1)-\mathrm{O}(1) & 1.360(18) \\ \mathrm{N}(1)-\mathrm{C}(32) & 1.43(2)\end{array}$




\begin{tabular}{|c|c|}
\hline $\operatorname{Th}(1)-\mathrm{O}(1)$ & $2.397(12)$ \\
\hline $\operatorname{Th}(1)-C(34)$ & $2.613(12)$ \\
\hline $\operatorname{Th}(1)-\mathrm{C}(21)$ & $2.666(9)$ \\
\hline $\operatorname{Th}(1)-C(15)$ & $2.841(7)$ \\
\hline $\operatorname{Th}(1)-\mathrm{C}(11)$ & $2.862(6)$ \\
\hline $\operatorname{Th}(1)-C(14)$ & $2.881(7)$ \\
\hline $\operatorname{Th}(1)-C(5)$ & $2.885(7)$ \\
\hline $\operatorname{Th}(1)-C(1)$ & $2.888(7)$ \\
\hline $\operatorname{Th}(1)-C(4)$ & $2.898(6)$ \\
\hline $\operatorname{Th}(1)-\mathrm{C}(2)$ & $2.903(6)$ \\
\hline $\operatorname{Th}(1)-\mathrm{C}(3)$ & $2.909(6)$ \\
\hline $\operatorname{Th}(1)-\mathrm{C}(12)$ & $2.914(7)$ \\
\hline$C(1)-C(2)$ & 1.4200 \\
\hline$C(1)-C(5)$ & 1.4200 \\
\hline$C(1)-C(6)$ & 1.5095 \\
\hline$C(2)-C(3)$ & 1.4200 \\
\hline $\mathrm{C}(2)-\mathrm{C}(7)$ & 1.5095 \\
\hline$C(3)-C(4)$ & 1.4200 \\
\hline $\mathrm{C}(3)-\mathrm{C}(8)$ & 1.5095 \\
\hline$C(4)-C(5)$ & 1.4200 \\
\hline $\mathrm{C}(4)-\mathrm{C}(9)$ & 1.5095 \\
\hline$C(5)-C(10)$ & 1.5095 \\
\hline $\mathrm{C}(11)-\mathrm{C}(12)$ & 1.4200 \\
\hline C(11)-C(15) & 1.4200 \\
\hline$C(11)-C(16)$ & 1.5095 \\
\hline $\mathrm{C}(12)-\mathrm{C}(13)$ & 1.4200 \\
\hline C(12)-C(17) & 1.5095 \\
\hline$C(13)-C(14)$ & 1.4200 \\
\hline$C(13)-C(18)$ & 1.5095 \\
\hline$C(14)-C(15)$ & 1.4200 \\
\hline $\mathrm{C}(14)-\mathrm{C}(19)$ & 1.5095 \\
\hline$C(15)-C(20)$ & 1.5095 \\
\hline$C(21)-C(22)$ & $1.558(17)$ \\
\hline $\mathrm{C}(21)-\mathrm{C}\left(22^{\prime}\right)$ & $1.568(19)$ \\
\hline$C(22)-C\left(23^{\prime}\right)$ & $0.86(3)$ \\
\hline $\mathrm{C}(22)-\mathrm{C}\left(22^{\prime}\right)$ & $1.119(19)$ \\
\hline
\end{tabular}




\begin{tabular}{|c|c|}
\hline$C(22)-C(23)$ & 1.3900 \\
\hline$C(22)-C(27)$ & 1.3900 \\
\hline$C(23)-C(24)$ & 1.3900 \\
\hline$C(23)-C\left(23^{\prime}\right)$ & $1.400(16)$ \\
\hline$C(24)-C(25)$ & 1.3900 \\
\hline$C(24)-C\left(24^{\prime}\right)$ & $1.83(2)$ \\
\hline$C(24)-C\left(23^{\prime}\right)$ & $1.88(2)$ \\
\hline$C(25)-C\left(24^{\prime}\right)$ & $0.90(3)$ \\
\hline$C(25)-C(26)$ & 1.3900 \\
\hline$C(25)-C\left(23^{\prime}\right)$ & $1.97(3)$ \\
\hline$C(25)-C\left(25^{\prime}\right)$ & $1.98(3)$ \\
\hline$C(26)-C\left(24^{\prime}\right)$ & $0.62(2)$ \\
\hline$C(26)-C\left(25^{\prime}\right)$ & $0.84(2)$ \\
\hline$C(26)-C(27)$ & 1.3900 \\
\hline$C(26)-C\left(23^{\prime}\right)$ & $1.63(2)$ \\
\hline$C(26)-C\left(26^{\prime}\right)$ & $1.81(2)$ \\
\hline$C(27)-C\left(22^{\prime}\right)$ & $0.90(3)$ \\
\hline$C(27)-C\left(23^{\prime}\right)$ & $1.038(15)$ \\
\hline$C(27)-C\left(27^{\prime}\right)$ & $1.399(19)$ \\
\hline$C(27)-C\left(24^{\prime}\right)$ & $1.58(3)$ \\
\hline$C(27)-C\left(26^{\prime}\right)$ & $1.838(18)$ \\
\hline $\mathrm{C}(27)-\mathrm{C}\left(25^{\prime}\right)$ & $1.91(3)$ \\
\hline$C\left(22^{\prime}\right)-C\left(23^{\prime}\right)$ & 1.3900 \\
\hline$C\left(22^{\prime}\right)-C\left(27^{\prime}\right)$ & 1.3900 \\
\hline$C\left(23^{\prime}\right)-C\left(24^{\prime}\right)$ & 1.3900 \\
\hline$C\left(24^{\prime}\right)-C\left(25^{\prime}\right)$ & 1.3900 \\
\hline$C\left(25^{\prime}\right)-C\left(26^{\prime}\right)$ & 1.3900 \\
\hline$C\left(26^{\prime}\right)-C\left(27^{\prime}\right)$ & 1.3900 \\
\hline$C(28)-C(29)$ & $1.35(2)$ \\
\hline C(28)-C(33) & $1.50(3)$ \\
\hline$C(29)-C(30)$ & $1.37(3)$ \\
\hline$C(30)-C(31)$ & $1.36(3)$ \\
\hline$C(31)-C(32)$ & $1.367(19)$ \\
\hline$C(32)-C(34)$ & $1.44(2)$ \\
\hline $\mathrm{C}(28)-\mathrm{N}(1)-\mathrm{O}(1)$ & $119.7(15)$ \\
\hline
\end{tabular}




\begin{tabular}{|c|c|}
\hline $\mathrm{C}(28)-\mathrm{N}(1)-\mathrm{C}(32)$ & $124.0(14)$ \\
\hline $\mathrm{O}(1)-\mathrm{N}(1)-\mathrm{C}(32)$ & $115.9(12)$ \\
\hline $\mathrm{O}(1)-\mathrm{Th}(1)-\mathrm{C}(34)$ & $63.5(4)$ \\
\hline $\mathrm{O}(1)-\mathrm{Th}(1)-\mathrm{C}(21)$ & $132.4(5)$ \\
\hline $\mathrm{C}(34)-\mathrm{Th}(1)-\mathrm{C}(21)$ & $73.1(5)$ \\
\hline $\mathrm{O}(1)-\mathrm{Th}(1)-\mathrm{C}(15)$ & $67.7(4)$ \\
\hline $\mathrm{C}(34)-\mathrm{Th}(1)-\mathrm{C}(15)$ & 101.2(4) \\
\hline $\mathrm{C}(21)-\operatorname{Th}(1)-\mathrm{C}(15)$ & $104.7(3)$ \\
\hline $\mathrm{O}(1)-\mathrm{Th}(1)-\mathrm{C}(11)$ & 79.9(4) \\
\hline $\mathrm{C}(34)-\mathrm{Th}(1)-\mathrm{C}(11)$ & $129.0(4)$ \\
\hline $\mathrm{C}(21)-\mathrm{Th}(1)-\mathrm{C}(11)$ & $116.6(2)$ \\
\hline$C(15)-\operatorname{Th}(1)-C(11)$ & $28.83(6)$ \\
\hline $\mathrm{O}(1)-\mathrm{Th}(1)-\mathrm{C}(14)$ & $89.5(4)$ \\
\hline $\mathrm{C}(34)-\mathrm{Th}(1)-\mathrm{C}(14)$ & $96.0(4)$ \\
\hline $\mathrm{C}(21)-\mathrm{Th}(1)-\mathrm{C}(14)$ & $76.1(2)$ \\
\hline $\mathrm{C}(15)-\mathrm{Th}(1)-\mathrm{C}(14)$ & $28.73(7)$ \\
\hline $\mathrm{C}(11)-\mathrm{Th}(1)-\mathrm{C}(14)$ & $47.17(9)$ \\
\hline $\mathrm{O}(1)-\mathrm{Th}(1)-\mathrm{C}(5)$ & 79.1(3) \\
\hline $\mathrm{C}(34)-\operatorname{Th}(1)-\mathrm{C}(5)$ & $110.4(4)$ \\
\hline $\mathrm{C}(21)-\mathrm{Th}(1)-\mathrm{C}(5)$ & $136.7(4)$ \\
\hline $\mathrm{C}(15)-\mathrm{Th}(1)-\mathrm{C}(5)$ & $116.1(2)$ \\
\hline $\mathrm{C}(11)-\operatorname{Th}(1)-\mathrm{C}(5)$ & $94.9(2)$ \\
\hline $\mathrm{C}(14)-\operatorname{Th}(1)-\mathrm{C}(5)$ & $141.95(19)$ \\
\hline $\mathrm{O}(1)-\mathrm{Th}(1)-\mathrm{C}(1)$ & $78.2(3)$ \\
\hline $\mathrm{C}(34)-\operatorname{Th}(1)-\mathrm{C}(1)$ & $85.2(4)$ \\
\hline $\mathrm{C}(21)-\mathrm{Th}(1)-\mathrm{C}(1)$ & $117.7(3)$ \\
\hline $\mathrm{C}(15)-\mathrm{Th}(1)-\mathrm{C}(1)$ & $137.1(2)$ \\
\hline $\mathrm{C}(11)-\mathrm{Th}(1)-\mathrm{C}(1)$ & $122.1(2)$ \\
\hline $\mathrm{C}(14)-\operatorname{Th}(1)-\mathrm{C}(1)$ & $165.7(2)$ \\
\hline $\mathrm{C}(5)-\mathrm{Th}(1)-\mathrm{C}(1)$ & $28.48(6)$ \\
\hline $\mathrm{O}(1)-\mathrm{Th}(1)-\mathrm{C}(4)$ & $106.1(3)$ \\
\hline $\mathrm{C}(34)-\operatorname{Th}(1)-\mathrm{C}(4)$ & $131.2(4)$ \\
\hline $\mathrm{C}(21)-\operatorname{Th}(1)-\mathrm{C}(4)$ & $117.1(4)$ \\
\hline$C(15)-\operatorname{Th}(1)-C(4)$ & $119.1(2)$ \\
\hline $\mathrm{C}(11)-\mathrm{Th}(1)-\mathrm{C}(4)$ & $91.0(2)$ \\
\hline $\mathrm{C}(14)-\mathrm{Th}(1)-\mathrm{C}(4)$ & $132.5(2)$ \\
\hline
\end{tabular}




\begin{tabular}{|c|c|}
\hline $\mathrm{C}(5)-\mathrm{Th}(1)-\mathrm{C}(4)$ & $28.43(6)$ \\
\hline $\mathrm{C}(1)-\mathrm{Th}(1)-\mathrm{C}(4)$ & $46.80(9)$ \\
\hline $\mathrm{O}(1)-\mathrm{Th}(1)-\mathrm{C}(2)$ & $104.7(3)$ \\
\hline $\mathrm{C}(34)-\mathrm{Th}(1)-\mathrm{C}(2)$ & $87.9(4)$ \\
\hline $\mathrm{C}(21)-\mathrm{Th}(1)-\mathrm{C}(2)$ & $91.8(3)$ \\
\hline$C(15)-\operatorname{Th}(1)-C(2)$ & $162.9(2)$ \\
\hline $\mathrm{C}(11)-\operatorname{Th}(1)-\mathrm{C}(2)$ & $137.4(2)$ \\
\hline$C(14)-\operatorname{Th}(1)-C(2)$ & $165.5(2)$ \\
\hline $\mathrm{C}(5)-\mathrm{Th}(1)-\mathrm{C}(2)$ & $46.78(9)$ \\
\hline $\mathrm{C}(1)-\mathrm{Th}(1)-\mathrm{C}(2)$ & $28.39(6)$ \\
\hline $\mathrm{C}(4)-\mathrm{Th}(1)-\mathrm{C}(2)$ & $46.67(8)$ \\
\hline $\mathrm{O}(1)-\mathrm{Th}(1)-\mathrm{C}(3)$ & $123.2(3)$ \\
\hline $\mathrm{C}(34)-\operatorname{Th}(1)-\mathrm{C}(3)$ & $114.9(4)$ \\
\hline $\mathrm{C}(21)-\mathrm{Th}(1)-\mathrm{C}(3)$ & $91.5(4)$ \\
\hline $\mathrm{C}(15)-\mathrm{Th}(1)-\mathrm{C}(3)$ & $143.5(2)$ \\
\hline $\mathrm{C}(11)-\mathrm{Th}(1)-\mathrm{C}(3)$ & $114.7(2)$ \\
\hline $\mathrm{C}(14)-\mathrm{Th}(1)-\mathrm{C}(3)$ & $142.0(2)$ \\
\hline $\mathrm{C}(5)-\mathrm{Th}(1)-\mathrm{C}(3)$ & $46.73(9)$ \\
\hline $\mathrm{C}(1)-\mathrm{Th}(1)-\mathrm{C}(3)$ & $46.70(8)$ \\
\hline $\mathrm{C}(4)-\mathrm{Th}(1)-\mathrm{C}(3)$ & $28.31(6)$ \\
\hline $\mathrm{C}(2)-\mathrm{Th}(1)-\mathrm{C}(3)$ & $28.29(6)$ \\
\hline $\mathrm{O}(1)-\mathrm{Th}(1)-\mathrm{C}(12)$ & $108.2(4)$ \\
\hline $\mathrm{C}(34)-\operatorname{Th}(1)-\mathrm{C}(12)$ & $142.7(4)$ \\
\hline $\mathrm{C}(21)-\mathrm{Th}(1)-\mathrm{C}(12)$ & $94.4(2)$ \\
\hline $\mathrm{C}(15)-\mathrm{Th}(1)-\mathrm{C}(12)$ & $47.04(8)$ \\
\hline $\mathrm{C}(11)-\mathrm{Th}(1)-\mathrm{C}(12)$ & $28.45(6)$ \\
\hline $\mathrm{C}(14)-\mathrm{Th}(1)-\mathrm{C}(12)$ & $46.72(8)$ \\
\hline $\mathrm{C}(5)-\mathrm{Th}(1)-\mathrm{C}(12)$ & $102.7(3)$ \\
\hline $\mathrm{C}(1)-\operatorname{Th}(1)-\mathrm{C}(12)$ & $130.4(2)$ \\
\hline $\mathrm{C}(4)-\mathrm{Th}(1)-\mathrm{C}(12)$ & $85.9(2)$ \\
\hline $\mathrm{C}(2)-\operatorname{Th}(1)-\mathrm{C}(12)$ & $128.2(2)$ \\
\hline $\mathrm{C}(3)-\mathrm{Th}(1)-\mathrm{C}(12)$ & $100.1(2)$ \\
\hline $\mathrm{N}(1)-\mathrm{O}(1)-\mathrm{Th}(1)$ & $125.4(9)$ \\
\hline$C(2)-C(1)-C(5)$ & 108.0 \\
\hline$C(2)-C(1)-C(6)$ & 126.0 \\
\hline$C(5)-C(1)-C(6)$ & 126.0 \\
\hline
\end{tabular}




\begin{tabular}{|c|c|}
\hline $\mathrm{C}(2)-\mathrm{C}(1)-\mathrm{Th}(1)$ & $76.4(2)$ \\
\hline$C(5)-C(1)-T h(1)$ & $75.6(2)$ \\
\hline $\mathrm{C}(6)-\mathrm{C}(1)-\mathrm{Th}(1)$ & $114.28(19)$ \\
\hline$C(1)-C(2)-C(3)$ & 108.0 \\
\hline$C(1)-C(2)-C(7)$ & 126.0 \\
\hline$C(3)-C(2)-C(7)$ & 126.0 \\
\hline $\mathrm{C}(1)-\mathrm{C}(2)-\mathrm{Th}(1)$ & $75.2(2)$ \\
\hline$C(3)-C(2)-T h(1)$ & $76.1(2)$ \\
\hline $\mathrm{C}(7)-\mathrm{C}(2)-\mathrm{Th}(1)$ & $114.9(2)$ \\
\hline$C(2)-C(3)-C(4)$ & 108.0 \\
\hline $\mathrm{C}(2)-\mathrm{C}(3)-\mathrm{C}(8)$ & 126.0 \\
\hline $\mathrm{C}(4)-\mathrm{C}(3)-\mathrm{C}(8)$ & 126.0 \\
\hline$C(2)-C(3)-T h(1)$ & $75.6(2)$ \\
\hline $\mathrm{C}(4)-\mathrm{C}(3)-\mathrm{Th}(1)$ & $75.4(2)$ \\
\hline $\mathrm{C}(8)-\mathrm{C}(3)-\mathrm{Th}(1)$ & $115.2(2)$ \\
\hline$C(5)-C(4)-C(3)$ & 108.0 \\
\hline$C(5)-C(4)-C(9)$ & 126.0 \\
\hline $\mathrm{C}(3)-\mathrm{C}(4)-\mathrm{C}(9)$ & 126.0 \\
\hline$C(5)-C(4)-T h(1)$ & $75.3(2)$ \\
\hline $\mathrm{C}(3)-\mathrm{C}(4)-\mathrm{Th}(1)$ & $76.3(2)$ \\
\hline $\mathrm{C}(9)-\mathrm{C}(4)-\mathrm{Th}(1)$ & $114.71(19)$ \\
\hline$C(4)-C(5)-C(1)$ & 108.0 \\
\hline $\mathrm{C}(4)-\mathrm{C}(5)-\mathrm{C}(10)$ & 126.0 \\
\hline$C(1)-C(5)-C(10)$ & 126.0 \\
\hline$C(4)-C(5)-T h(1)$ & $76.3(2)$ \\
\hline $\mathrm{C}(1)-\mathrm{C}(5)-\mathrm{Th}(1)$ & $75.9(2)$ \\
\hline$C(10)-C(5)-T h(1)$ & $114.15(19)$ \\
\hline $\mathrm{C}(12)-\mathrm{C}(11)-\mathrm{C}(15)$ & 108.0 \\
\hline$C(12)-C(11)-C(16)$ & 126.0 \\
\hline$C(15)-C(11)-C(16)$ & 126.0 \\
\hline $\mathrm{C}(12)-\mathrm{C}(11)-\mathrm{Th}(1)$ & $77.8(2)$ \\
\hline $\mathrm{C}(15)-\mathrm{C}(11)-\mathrm{Th}(1)$ & $74.8(2)$ \\
\hline $\mathrm{C}(16)-\mathrm{C}(11)-\mathrm{Th}(1)$ & $113.78(18)$ \\
\hline $\mathrm{C}(13)-\mathrm{C}(12)-\mathrm{C}(11)$ & 108.0 \\
\hline $\mathrm{C}(13)-\mathrm{C}(12)-\mathrm{C}(17)$ & 126.0 \\
\hline$C(11)-C(12)-C(17)$ & 126.0 \\
\hline
\end{tabular}




\begin{tabular}{|c|c|}
\hline $\mathrm{C}(13)-\mathrm{C}(12)-\mathrm{Th}(1)$ & $76.37(19)$ \\
\hline $\mathrm{C}(11)-\mathrm{C}(12)-\mathrm{Th}(1)$ & $73.8(2)$ \\
\hline $\mathrm{C}(17)-\mathrm{C}(12)-\mathrm{Th}(1)$ & $116.0(2)$ \\
\hline$C(12)-C(13)-C(14)$ & 108.0 \\
\hline $\mathrm{C}(12)-\mathrm{C}(13)-\mathrm{C}(18)$ & 126.0 \\
\hline $\mathrm{C}(14)-\mathrm{C}(13)-\mathrm{C}(18)$ & 126.0 \\
\hline $\mathrm{C}(12)-\mathrm{C}(13)-\mathrm{Th}(1)$ & $75.5(2)$ \\
\hline$C(14)-C(13)-T h(1)$ & $74.1(2)$ \\
\hline $\mathrm{C}(18)-\mathrm{C}(13)-\mathrm{Th}(1)$ & $116.50(18)$ \\
\hline$C(15)-C(14)-C(13)$ & 108.0 \\
\hline$C(15)-C(14)-C(19)$ & 126.0 \\
\hline$C(13)-C(14)-C(19)$ & 126.0 \\
\hline $\mathrm{C}(15)-\mathrm{C}(14)-\mathrm{Th}(1)$ & $74.09(18)$ \\
\hline$C(13)-C(14)-\operatorname{Th}(1)$ & $77.6(2)$ \\
\hline $\mathrm{C}(19)-\mathrm{C}(14)-\mathrm{Th}(1)$ & $114.6(2)$ \\
\hline$C(14)-C(15)-C(11)$ & 108.0 \\
\hline$C(14)-C(15)-C(20)$ & 126.0 \\
\hline$C(11)-C(15)-C(20)$ & 126.0 \\
\hline $\mathrm{C}(14)-\mathrm{C}(15)-\mathrm{Th}(1)$ & $77.18(18)$ \\
\hline$C(11)-C(15)-T h(1)$ & $76.4(2)$ \\
\hline $\mathrm{C}(20)-\mathrm{C}(15)-\mathrm{Th}(1)$ & $112.9(2)$ \\
\hline $\mathrm{C}(22)-\mathrm{C}(21)-\mathrm{C}\left(22^{\prime}\right)$ & $41.9(7)$ \\
\hline $\mathrm{C}(22)-\mathrm{C}(21)-\mathrm{Th}(1)$ & $124.0(12)$ \\
\hline $\mathrm{C}\left(22^{\prime}\right)-\mathrm{C}(21)-\mathrm{Th}(1)$ & $124.2(13)$ \\
\hline $\mathrm{C}\left(23^{\prime}\right)-\mathrm{C}(22)-\mathrm{C}\left(22^{\prime}\right)$ & $88.3(16)$ \\
\hline $\mathrm{C}\left(23^{\prime}\right)-\mathrm{C}(22)-\mathrm{C}(23)$ & $72.7(11)$ \\
\hline $\mathrm{C}\left(22^{\prime}\right)-\mathrm{C}(22)-\mathrm{C}(23)$ & $159.3(16)$ \\
\hline $\mathrm{C}\left(23^{\prime}\right)-\mathrm{C}(22)-\mathrm{C}(27)$ & $48.2(11)$ \\
\hline$C\left(22^{\prime}\right)-C(22)-C(27)$ & $40.2(15)$ \\
\hline$C(23)-C(22)-C(27)$ & 120.0 \\
\hline$C\left(23^{\prime}\right)-C(22)-C(21)$ & $156(2)$ \\
\hline $\mathrm{C}\left(22^{\prime}\right)-\mathrm{C}(22)-\mathrm{C}(21)$ & $69.5(15)$ \\
\hline$C(23)-C(22)-C(21)$ & $130.4(15)$ \\
\hline$C(27)-C(22)-C(21)$ & $109.6(15)$ \\
\hline $\mathrm{C}(22)-\mathrm{C}(23)-\mathrm{C}(24)$ & 120.0 \\
\hline $\mathrm{C}(22)-\mathrm{C}(23)-\mathrm{C}\left(23^{\prime}\right)$ & $35.8(12)$ \\
\hline
\end{tabular}




\begin{tabular}{|c|c|}
\hline$C(24)-C(23)-C\left(23^{\prime}\right)$ & $84.6(12)$ \\
\hline$C(23)-C(24)-C(25)$ & 120.0 \\
\hline$C(23)-C(24)-C\left(24^{\prime}\right)$ & $92.0(9)$ \\
\hline$C(25)-C(24)-C\left(24^{\prime}\right)$ & $28.6(10)$ \\
\hline$C(23)-C(24)-C\left(23^{\prime}\right)$ & $47.9(7)$ \\
\hline$C(25)-C(24)-C\left(23^{\prime}\right)$ & $72.2(7)$ \\
\hline$C\left(24^{\prime}\right)-C(24)-C\left(23^{\prime}\right)$ & $44.0(4)$ \\
\hline$C\left(24^{\prime}\right)-C(25)-C(26)$ & $20(2)$ \\
\hline$C\left(24^{\prime}\right)-C(25)-C(24)$ & $103.8(16)$ \\
\hline$C(26)-C(25)-C(24)$ & 120.0 \\
\hline$C\left(24^{\prime}\right)-C(25)-C\left(23^{\prime}\right)$ & $39.2(15)$ \\
\hline$C(26)-C(25)-C\left(23^{\prime}\right)$ & $54.7(4)$ \\
\hline$C(24)-C(25)-C\left(23^{\prime}\right)$ & $65.4(4)$ \\
\hline$C\left(24^{\prime}\right)-C(25)-C\left(25^{\prime}\right)$ & $38.0(13)$ \\
\hline$C(26)-C(25)-C\left(25^{\prime}\right)$ & $20.4(9)$ \\
\hline$C(24)-C(25)-C\left(25^{\prime}\right)$ & $140.4(9)$ \\
\hline$C\left(23^{\prime}\right)-C(25)-C\left(25^{\prime}\right)$ & $75.1(9)$ \\
\hline$C\left(24^{\prime}\right)-C(26)-C\left(25^{\prime}\right)$ & $144(5)$ \\
\hline$C\left(24^{\prime}\right)-C(26)-C(25)$ & $29(3)$ \\
\hline$C\left(25^{\prime}\right)-C(26)-C(25)$ & $124(2)$ \\
\hline$C\left(24^{\prime}\right)-C(26)-C(27)$ & $96(3)$ \\
\hline$C\left(25^{\prime}\right)-C(26)-C(27)$ & $116(2)$ \\
\hline$C(25)-C(26)-C(27)$ & 120.0 \\
\hline$C\left(24^{\prime}\right)-C(26)-C\left(23^{\prime}\right)$ & $57(2)$ \\
\hline$C\left(25^{\prime}\right)-C(26)-C\left(23^{\prime}\right)$ & $154(3)$ \\
\hline$C(25)-C(26)-C\left(23^{\prime}\right)$ & $81.0(8)$ \\
\hline$C(27)-C(26)-C\left(23^{\prime}\right)$ & $39.3(8)$ \\
\hline$C\left(24^{\prime}\right)-C(26)-C\left(26^{\prime}\right)$ & $162(4)$ \\
\hline$C\left(25^{\prime}\right)-C(26)-C\left(26^{\prime}\right)$ & $47.8(14)$ \\
\hline$C(25)-C(26)-C\left(26^{\prime}\right)$ & $168.6(12)$ \\
\hline$C(27)-C(26)-C\left(26^{\prime}\right)$ & $68.8(11)$ \\
\hline $\mathrm{C}\left(23^{\prime}\right)-\mathrm{C}(26)-\mathrm{C}\left(26^{\prime}\right)$ & $108.1(16)$ \\
\hline$C\left(22^{\prime}\right)-C(27)-C\left(23^{\prime}\right)$ & $91.4(18)$ \\
\hline $\mathrm{C}\left(22^{\prime}\right)-\mathrm{C}(27)-\mathrm{C}(26)$ & $171(3)$ \\
\hline $\mathrm{C}\left(23^{\prime}\right)-\mathrm{C}(27)-\mathrm{C}(26)$ & $82.7(16)$ \\
\hline$C\left(22^{\prime}\right)-C(27)-C(22)$ & $53.4(12)$ \\
\hline
\end{tabular}




\begin{tabular}{|c|c|}
\hline $\mathrm{C}\left(23^{\prime}\right)-\mathrm{C}(27)-\mathrm{C}(22)$ & $38.0(16)$ \\
\hline$C(26)-C(27)-C(22)$ & 120.0 \\
\hline$C\left(22^{\prime}\right)-C(27)-C\left(27^{\prime}\right)$ & $70.6(15)$ \\
\hline $\mathrm{C}\left(23^{\prime}\right)-\mathrm{C}(27)-\mathrm{C}\left(27^{\prime}\right)$ & $162(3)$ \\
\hline$C(26)-C(27)-C\left(27^{\prime}\right)$ & $114.7(14)$ \\
\hline $\mathrm{C}(22)-\mathrm{C}(27)-\mathrm{C}\left(27^{\prime}\right)$ & $123.8(15)$ \\
\hline $\mathrm{C}\left(22^{\prime}\right)-\mathrm{C}(27)-\mathrm{C}\left(24^{\prime}\right)$ & $151.2(15)$ \\
\hline $\mathrm{C}\left(23^{\prime}\right)-\mathrm{C}(27)-\mathrm{C}\left(24^{\prime}\right)$ & $59.9(13)$ \\
\hline$C(26)-C(27)-C\left(24^{\prime}\right)$ & $23.1(9)$ \\
\hline$C(22)-C(27)-C\left(24^{\prime}\right)$ & $97.8(8)$ \\
\hline $\mathrm{C}\left(27^{\prime}\right)-\mathrm{C}(27)-\mathrm{C}\left(24^{\prime}\right)$ & $137.7(17)$ \\
\hline $\mathrm{C}\left(22^{\prime}\right)-\mathrm{C}(27)-\mathrm{C}\left(26^{\prime}\right)$ & $119.2(16)$ \\
\hline $\mathrm{C}\left(23^{\prime}\right)-\mathrm{C}(27)-\mathrm{C}\left(26^{\prime}\right)$ & $149(2)$ \\
\hline$C(26)-C(27)-C\left(26^{\prime}\right)$ & $66.4(11)$ \\
\hline $\mathrm{C}(22)-\mathrm{C}(27)-\mathrm{C}\left(26^{\prime}\right)$ & $170.3(16)$ \\
\hline $\mathrm{C}\left(27^{\prime}\right)-\mathrm{C}(27)-\mathrm{C}\left(26^{\prime}\right)$ & $48.6(5)$ \\
\hline $\mathrm{C}\left(24^{\prime}\right)-\mathrm{C}(27)-\mathrm{C}\left(26^{\prime}\right)$ & $89.2(13)$ \\
\hline $\mathrm{C}\left(22^{\prime}\right)-\mathrm{C}(27)-\mathrm{C}\left(25^{\prime}\right)$ & $162.4(19)$ \\
\hline $\mathrm{C}\left(23^{\prime}\right)-\mathrm{C}(27)-\mathrm{C}\left(25^{\prime}\right)$ & $106(2)$ \\
\hline$C(26)-C(27)-C\left(25^{\prime}\right)$ & $23.2(9)$ \\
\hline $\mathrm{C}(22)-\mathrm{C}(27)-\mathrm{C}\left(25^{\prime}\right)$ & 143.2(9) \\
\hline$C\left(27^{\prime}\right)-C(27)-C\left(25^{\prime}\right)$ & $92.1(10)$ \\
\hline $\mathrm{C}\left(24^{\prime}\right)-\mathrm{C}(27)-\mathrm{C}\left(25^{\prime}\right)$ & $45.7(8)$ \\
\hline$C\left(26^{\prime}\right)-C(27)-C\left(25^{\prime}\right)$ & $43.5(6)$ \\
\hline$C(27)-C\left(22^{\prime}\right)-C(22)$ & $86.4(18)$ \\
\hline $\mathrm{C}(27)-\mathrm{C}\left(22^{\prime}\right)-\mathrm{C}\left(23^{\prime}\right)$ & $48.3(10)$ \\
\hline $\mathrm{C}(22)-\mathrm{C}\left(22^{\prime}\right)-\mathrm{C}\left(23^{\prime}\right)$ & $38.1(15)$ \\
\hline $\mathrm{C}(27)-\mathrm{C}\left(22^{\prime}\right)-\mathrm{C}\left(27^{\prime}\right)$ & $71.8(10)$ \\
\hline $\mathrm{C}(22)-\mathrm{C}\left(22^{\prime}\right)-\mathrm{C}\left(27^{\prime}\right)$ & $157.4(16)$ \\
\hline $\mathrm{C}\left(23^{\prime}\right)-\mathrm{C}\left(22^{\prime}\right)-\mathrm{C}\left(27^{\prime}\right)$ & 120.0 \\
\hline $\mathrm{C}(27)-\mathrm{C}\left(22^{\prime}\right)-\mathrm{C}(21)$ & $154.3(19)$ \\
\hline$C(22)-C\left(22^{\prime}\right)-C(21)$ & $68.5(13)$ \\
\hline $\mathrm{C}\left(23^{\prime}\right)-\mathrm{C}\left(22^{\prime}\right)-\mathrm{C}(21)$ & $106.2(14)$ \\
\hline$C\left(27^{\prime}\right)-C\left(22^{\prime}\right)-C(21)$ & $133.8(14)$ \\
\hline$C(22)-C\left(23^{\prime}\right)-C(27)$ & $94(2)$ \\
\hline$C(22)-C\left(23^{\prime}\right)-C\left(24^{\prime}\right)$ & 171(3) \\
\hline
\end{tabular}




\begin{tabular}{|c|c|}
\hline $\mathrm{C}(27)-\mathrm{C}\left(23^{\prime}\right)-\mathrm{C}\left(24^{\prime}\right)$ & $79.8(16)$ \\
\hline $\mathrm{C}(22)-\mathrm{C}\left(23^{\prime}\right)-\mathrm{C}\left(22^{\prime}\right)$ & $53.6(13)$ \\
\hline $\mathrm{C}(27)-\mathrm{C}\left(23^{\prime}\right)-\mathrm{C}\left(22^{\prime}\right)$ & $40.3(16)$ \\
\hline$C\left(24^{\prime}\right)-C\left(23^{\prime}\right)-C\left(22^{\prime}\right)$ & 120.0 \\
\hline$C(22)-C\left(23^{\prime}\right)-C(23)$ & $71.4(12)$ \\
\hline$C(27)-C\left(23^{\prime}\right)-C(23)$ & $162(3)$ \\
\hline$C\left(24^{\prime}\right)-C\left(23^{\prime}\right)-C(23)$ & $113.6(15)$ \\
\hline$C\left(22^{\prime}\right)-C\left(23^{\prime}\right)-C(23)$ & $124.4(14)$ \\
\hline$C(22)-C\left(23^{\prime}\right)-C(26)$ & $150(2)$ \\
\hline$C(27)-C\left(23^{\prime}\right)-C(26)$ & $58.0(11)$ \\
\hline$C\left(24^{\prime}\right)-C\left(23^{\prime}\right)-C(26)$ & $22.2(10)$ \\
\hline$C\left(22^{\prime}\right)-C\left(23^{\prime}\right)-C(26)$ & $98.0(9)$ \\
\hline$C(23)-C\left(23^{\prime}\right)-C(26)$ & $133(2)$ \\
\hline$C(22)-C\left(23^{\prime}\right)-C(24)$ & $118.4(15)$ \\
\hline$C(27)-C\left(23^{\prime}\right)-C(24)$ & $143(2)$ \\
\hline$C\left(24^{\prime}\right)-C\left(23^{\prime}\right)-C(24)$ & $66.1(11)$ \\
\hline$C\left(22^{\prime}\right)-C\left(23^{\prime}\right)-C(24)$ & $164.7(16)$ \\
\hline$C(23)-C\left(23^{\prime}\right)-C(24)$ & $47.5(7)$ \\
\hline$C(26)-C\left(23^{\prime}\right)-C(24)$ & $86.5(13)$ \\
\hline$C(22)-C\left(23^{\prime}\right)-C(25)$ & $158(3)$ \\
\hline$C(27)-C\left(23^{\prime}\right)-C(25)$ & $102.1(18)$ \\
\hline$C\left(24^{\prime}\right)-C\left(23^{\prime}\right)-C(25)$ & $24.2(10)$ \\
\hline$C\left(22^{\prime}\right)-C\left(23^{\prime}\right)-C(25)$ & $141.0(9)$ \\
\hline$C(23)-C\left(23^{\prime}\right)-C(25)$ & $89.7(13)$ \\
\hline$C(26)-C\left(23^{\prime}\right)-C(25)$ & $44.3(7)$ \\
\hline$C(24)-C\left(23^{\prime}\right)-C(25)$ & $42.3(6)$ \\
\hline$C(26)-C\left(24^{\prime}\right)-C(25)$ & $131(5)$ \\
\hline$C(26)-C\left(24^{\prime}\right)-C\left(23^{\prime}\right)$ & $101(3)$ \\
\hline$C(25)-C\left(24^{\prime}\right)-C\left(23^{\prime}\right)$ & $117(2)$ \\
\hline$C(26)-C\left(24^{\prime}\right)-C\left(25^{\prime}\right)$ & $21(3)$ \\
\hline$C(25)-C\left(24^{\prime}\right)-C\left(25^{\prime}\right)$ & $119(2)$ \\
\hline $\mathrm{C}\left(23^{\prime}\right)-\mathrm{C}\left(24^{\prime}\right)-\mathrm{C}\left(25^{\prime}\right)$ & 120.0 \\
\hline$C(26)-C\left(24^{\prime}\right)-C(27)$ & $61(2)$ \\
\hline$C(25)-C\left(24^{\prime}\right)-C(27)$ & $151(3)$ \\
\hline$C\left(23^{\prime}\right)-C\left(24^{\prime}\right)-C(27)$ & $40.3(7)$ \\
\hline$C\left(25^{\prime}\right)-C\left(24^{\prime}\right)-C(27)$ & $79.7(7)$ \\
\hline
\end{tabular}




\begin{tabular}{|c|c|}
\hline $\mathrm{C}(26)-\mathrm{C}\left(24^{\prime}\right)-\mathrm{C}(24)$ & $155(5)$ \\
\hline$C(25)-C\left(24^{\prime}\right)-C(24)$ & $47.6(11)$ \\
\hline$C\left(23^{\prime}\right)-C\left(24^{\prime}\right)-C(24)$ & $69.9(11)$ \\
\hline$C\left(25^{\prime}\right)-C\left(24^{\prime}\right)-C(24)$ & $162.7(15)$ \\
\hline $\mathrm{C}(27)-\mathrm{C}\left(24^{\prime}\right)-\mathrm{C}(24)$ & $109.1(15)$ \\
\hline$C(26)-C\left(25^{\prime}\right)-C\left(26^{\prime}\right)$ & $106(2)$ \\
\hline$C(26)-C\left(25^{\prime}\right)-C\left(24^{\prime}\right)$ & $15(2)$ \\
\hline $\mathrm{C}\left(26^{\prime}\right)-\mathrm{C}\left(25^{\prime}\right)-\mathrm{C}\left(24^{\prime}\right)$ & 120.0 \\
\hline $\mathrm{C}(26)-\mathrm{C}\left(25^{\prime}\right)-\mathrm{C}(27)$ & $40.9(16)$ \\
\hline$C\left(26^{\prime}\right)-C\left(25^{\prime}\right)-C(27)$ & $65.5(6)$ \\
\hline $\mathrm{C}\left(24^{\prime}\right)-\mathrm{C}\left(25^{\prime}\right)-\mathrm{C}(27)$ & $54.5(5)$ \\
\hline$C(26)-C\left(25^{\prime}\right)-C(25)$ & $35.5(16)$ \\
\hline$C\left(26^{\prime}\right)-C\left(25^{\prime}\right)-C(25)$ & $140.4(10)$ \\
\hline $\mathrm{C}\left(24^{\prime}\right)-\mathrm{C}\left(25^{\prime}\right)-\mathrm{C}(25)$ & $23.5(10)$ \\
\hline $\mathrm{C}(27)-\mathrm{C}\left(25^{\prime}\right)-\mathrm{C}(25)$ & $76.4(8)$ \\
\hline $\mathrm{C}\left(27^{\prime}\right)-\mathrm{C}\left(26^{\prime}\right)-\mathrm{C}\left(25^{\prime}\right)$ & 120.0 \\
\hline $\mathrm{C}\left(27^{\prime}\right)-\mathrm{C}\left(26^{\prime}\right)-\mathrm{C}(26)$ & $93.7(9)$ \\
\hline $\mathrm{C}\left(25^{\prime}\right)-\mathrm{C}\left(26^{\prime}\right)-\mathrm{C}(26)$ & $26.5(9)$ \\
\hline $\mathrm{C}\left(27^{\prime}\right)-\mathrm{C}\left(26^{\prime}\right)-\mathrm{C}(27)$ & $49.0(9)$ \\
\hline$C\left(25^{\prime}\right)-C\left(26^{\prime}\right)-C(27)$ & $71.0(9)$ \\
\hline$C(26)-C\left(26^{\prime}\right)-C(27)$ & $44.8(4)$ \\
\hline $\mathrm{C}\left(26^{\prime}\right)-\mathrm{C}\left(27^{\prime}\right)-\mathrm{C}\left(22^{\prime}\right)$ & 120.0 \\
\hline$C\left(26^{\prime}\right)-C\left(27^{\prime}\right)-C(27)$ & $82.4(11)$ \\
\hline $\mathrm{C}\left(22^{\prime}\right)-\mathrm{C}\left(27^{\prime}\right)-\mathrm{C}(27)$ & $37.6(11)$ \\
\hline $\mathrm{N}(1)-\mathrm{C}(28)-\mathrm{C}(29)$ & $118.2(17)$ \\
\hline $\mathrm{N}(1)-\mathrm{C}(28)-\mathrm{C}(33)$ & $116.6(16)$ \\
\hline $\mathrm{C}(29)-\mathrm{C}(28)-\mathrm{C}(33)$ & $125.1(18)$ \\
\hline$C(28)-C(29)-C(30)$ & 121.1(17) \\
\hline$C(31)-C(30)-C(29)$ & $119.4(15)$ \\
\hline $\mathrm{C}(30)-\mathrm{C}(31)-\mathrm{C}(32)$ & $123.3(17)$ \\
\hline $\mathrm{C}(31)-\mathrm{C}(32)-\mathrm{N}(1)$ & $113.9(15)$ \\
\hline $\mathrm{C}(31)-\mathrm{C}(32)-\mathrm{C}(34)$ & $130.8(15)$ \\
\hline $\mathrm{N}(1)-\mathrm{C}(32)-\mathrm{C}(34)$ & $115.3(11)$ \\
\hline $\mathrm{C}(32)-\mathrm{C}(34)-\mathrm{Th}(1)$ & $114.0(8)$ \\
\hline
\end{tabular}


References:

${ }^{1}$ Pangborn, A.; Giardello, M.; Grubbs, R. H.; Rosen, R.; Timmers, F. Organometallics 1996, 15, 1518-1520.

${ }^{2}$ Fagan, P. J.; Manriquez, J. M.; Maatta, E. A.; Seyam, A. M.; Marks, T. J. J. Am. Chem. Soc. 1981, 103, 66506667.

${ }^{3}$ SMART 4, 1996, Bruker AXS, Inc.: Madison, WI 53719.

${ }^{4}$ SAINT 5.050, 1998, Bruker AXS, Inc.: Madison WI 53719.

${ }^{5}$ SADABS 1.0, 1996, George Sheldrick, University of Göttingen, Germany.

${ }^{6}$ SHELXTL 5.10, 1997, Bruker AXS, Inc.: Madison, WI 53719.

${ }^{5}$ APEX II 1.08, 2004, Bruker AXS, Inc., Madison, Wisconsin 53719.

${ }^{6}$ SAINT+ 7.06, 2003, Bruker AXS, Inc., Madison, Wisconsin 53719.

${ }^{7}$ SADABS 2.03, 2001, George Sheldrick, University of Göttingen, Germany.

${ }^{8}$ SHELXTL 6.10, 2000, Bruker AXS, Inc., Madison, Wisconsin 53719. 